\title{
Cleaning Up The Harbour: \\ The Hamilton Harbour \\ Remedial Action Plan as a Sustainable \\ Common Property Institution
}

by

Allison Bone, B.A.(Hons.)

A thesis submitted to

the Faculty of Graduate Studies and Research

in partial fulfillment of

the requirements for the degree of

Master of Arts

Institute of Political Economy

Carleton University

Ottawa, Ontario

May 2009

(c) 2009, Allison Bone 
Library and

Archives Canada

Published Heritage

Branch

395 Wellington Street

Ottawa ON K1A 0N4

Canada
Bibliothèque et

Archives Canada

Direction du

Patrimoine de l'édition

395 , rue Wellington

Ottawa ON K1A ON4

Canada

Your file Votre référence

ISBN: 978-0-494-52022-2

Our file Notre référence

ISBN: 978-0-494-52022-2

NOTICE:

The author has granted a nonexclusive license allowing Library and Archives Canada to reproduce, publish, archive, preserve, conserve, communicate to the public by telecommunication or on the Internet, loan, distribute and sell theses worldwide, for commercial or noncommercial purposes, in microform, paper, electronic and/or any other formats.

The author retains copyright ownership and moral rights in this thesis. Neither the thesis nor substantial extracts from it may be printed or otherwise reproduced without the author's permission.
AVIS:

L'auteur a accordé une licence non exclusive permettant à la Bibliothèque et Archives Canada de reproduire, publier, archiver, sauvegarder, conserver, transmettre au public par télécommunication ou par l'Internet, prêter, distribuer et vendre des thèses partout dans le monde, à des fins commerciales ou autres, sur support microforme, papier, électronique et/ou autres formats.

L'auteur conserve la propriété du droit d'auteur et des droits moraux qui protège cette thèse. $\mathrm{Ni}$ la thèse ni des extraits substantiels de celle-ci ne doivent être imprimés ou autrement reproduits sans son autorisation.
In compliance with the Canadian

Privacy Act some supporting forms may have been removed from this thesis.

While these forms may be included in the document page count, their removal does not represent any loss of content from the thesis.
Conformément à la loi canadienne sur la protection de la vie privée, quelques formulaires secondaires ont été enlevés de cette thèse.

Bien que ces formulaires aient inclus dans la pagination, il n'y aura aucun contenu manquant.

\section{Canada}




\begin{abstract}
This thesis argues that the challenges that the Hamilton Harbour Remedial Action Plan (RAP) faces in restoring the Hamilton Harbour are in part due to its inability to meet some of Elinor Ostrom's design principles for sustainable common pool resource governance institutions. This thesis uses documentation about the Hamilton Harbour RAP as well as documentation produced by the Bay Area Restoration Council, the stakeholder group charged with promoting, assessing and monitoring the Hamilton Harbour RAP, and interviews in order to assess how the RAP meets these principles. The Hamilton Harbour RAP has been successful, but improvements could be made in order to ensure its success in the future.
\end{abstract}




\section{Acknowledgements}

l'd like to extend my thanks to Stephan Schott, for his guidance and supervision, as well as Peter Andrée for offering his insightful feedback. l'd also like to thank those associated with the Hamilton Harbour Remedial Action Plan who took the time to participate in my research, as well as answer any additional questions that I had and the staff at BARC who graciously allowed me to use their library for research: your passion and dedication to the restoration of the harbour is truly inspiring. Last but not least, I would like to thank my parents for their love and support, which means the world to me. 


\section{Table of Contents}

Abstract

Acknowledgements

Page

Table of Contents

ii

List of Acronyms

iii

List of Tables

iv

List of Appendices

vi

vii

viii

1 Chapter 1: Water, pollution, and the Hamilton Harbour 1 Introduction

Thesis Overview

2 Chapter 2: Theory and Methods 11

$\begin{array}{lll}2.1 & 11\end{array}$

2.2 Stakeholders 13

2.3 Design Principles for Sustainable Collective Action Regimes 14

$2.4 \quad$ Reviewing Hamilton Harbour RAP literature 19

$\begin{array}{ll}2.5 & \text { Analysing BARC documentation } \\ 2.6 & 19\end{array}$

$\begin{array}{ll}2.6 & 22\end{array}$

$\begin{array}{lll}2.7 & \text { Summary } & 23\end{array}$

3 Chapter 3: Politics, Legislation, and Players 24

3.1 It began with the International Joint Commission... 24

3.2 The Great Lakes Water Quality Agreement 26

$3.21 \quad$ GLWQA: a history 26

3.22 GLWQA: Area's of Concern 28

3.23 GLWQA: Remedial Action Plans 29

3.24 GLWQA: Lakewide Management Plans 32

$3.25 \quad$ GLWQA: Public participation 33

$3.26 \quad$ GLWQA: Role of states and provinces 33

3.3 The Great Lakes Charter 34

3.4 The Canada-Ontario Agreement 35

3.5 Pollution legislation in Canada and Ontario 38

$\begin{array}{lll}3.6 & \text { Summary } & 41\end{array}$

$4 \quad$ Chapter 4: Hamilton Harbour and its caretakers 44

4.1 Hamilton Harbour: A brief history 44

$\begin{array}{ll}4.2 & \text { Land and water use } \\ 45\end{array}$

$\begin{array}{lll}4.3 & \text { Fisheries } & 47\end{array}$

$\begin{array}{lll}4.4 & \text { Pollutants } & 49\end{array}$

4.5 Taking care of Hamilton Harbour: Bay Area Restoration
Council

$4.51 \quad$ History: before BARC was formed 52

4.52 The formation of BARC 55 
Table of Contents Continued

4.6 Taking care of Hamilton Harbour: Bay Area Implementation Team $\quad 57$

$\begin{array}{lll}4.7 & \text { Summary } & 59\end{array}$

$5 \quad$ Chapter 5: Designing a collective action group 61

5.1 Well Defined Boundary for the Resource 62

5.2 Proportional Equivalence between Benefits and Costs 66

5.3 The Presence of a Collective Choice $\begin{array}{ll}\text { Arrangement } & 70\end{array}$

$\begin{array}{lll}5.4 & \text { Monitoring } & 80\end{array}$

5.5 Graduated Sanctions 86

5.6 Conflict Resolution Mechanisms 92

5.7 Minimal Recognition of Rights 94

5.8 A new design principle: distribution of resources (financial and human) 97

$\begin{array}{lll}5.9 & \text { Summary } & 101\end{array}$

6 Chapter 6: Recommendations 104

6.1 Review of Thesis 104

6.2 Recommendations 107

$\begin{array}{lll}6.3 & \text { Summary } & 112\end{array}$

Appendices

Appendix A Beneficial Use Impairments $\quad 115$

Appendix B Remedial Action Plans 116

Appendix C Map of Hamilton Harbour in 1835

Appendix D Map of Hamilton Harbour in $1989 \quad 118$

Appendix E Questions for the members of BARC 119

Appendix F Questions for the members of BARC partner $\quad 120$

Appendix G Questions for the member of the IJC 121

$\begin{array}{ll}\text { Works Cited } & 122\end{array}$ 


\section{List of Tables and Charts}

Table 1: Hamilton Harbour RAP Organization $\quad 7$

Table 2: Analyzing BARC documents $\quad 21$

Table 3: Stages of the Remedial Action Plans 31

Table 4: Past Expenditures for the HH RAP - 2000 and before 67

Table 5: Preliminary Cost Expenditures for the HH RAP 2000-2015 68 


$\begin{array}{ll}\text { AOC } & \text { Area of Concern } \\ \text { BAIT } & \text { Bay Area Implementation Team } \\ \text { BARC } & \text { Bay Area Restoration Council } \\ \text { CAC } & \text { Citizen Advisory Council } \\ \text { CEPA } & \text { Canadian Environmental Protection Act } \\ \text { COA } & \text { Canada - Ontario Agreement } \\ \text { CoA } & \text { Certificate of Approval } \\ \text { CPR } & \text { Common Pool Resources } \\ \text { CSO } & \text { Combined Sewer Outflows } \\ \text { EPA } & \text { Environmental Protection Act (Ontario) } \\ \text { GLWQA } & \text { Great Lakes Water Quality Agreement } \\ \text { HHC } & \text { Hamilton Harbour Commissioners } \\ \text { HPA } & \text { Hamilton Port Authority } \\ \text { IJC } & \text { International Joint Commission } \\ \text { LaMP } & \text { Lakewide Management Plan } \\ \text { LURA } & \text { Land Use Research Association } \\ \text { MISA } & \text { Municipal/Industrial Strategy for Abatement } \\ \text { MOE } & \text { Ministry of the Environment (Ontario) } \\ \text { OPAC } & \text { Ontario Public Advisory Council } \\ \text { OWRA } & \text { Ontario Water Resources Act } \\ \text { RAP } & \text { Remedial Action Plan } \\ \text { TSH } & \text { Toward Safe Harbours } \\ & \end{array}$




\section{List of Appendices}
A Beneficial Use Impairments
B Remedial Action Plans
C Map of Hamilton Harbour in 1835
D Map of Hamilton Harbour in 1989
E The questions for the members of BARC
F Questions for the members of partner organizations of BARC
G Questions for the member of the IJC 


\section{Chapter 1: Water, pollution, and the Hamilton Harbour}

"For that which is common to the greatest number has the least care bestowed upon it. Every one thinks chiefly of his own, hardly at all of the common interest and only when he is himself concerned as an individual" (Aristotle as quoted in Machan, 2001, xii)

\subsection{Introduction}

The commons, particularly common natural resources such as forests, land, fisheries and water, have often been a cause of tension amongst its users who compete for the ability to use and consume the resources. When a value is placed on the resource, the competition increases and the resource can be overexploited, as each user attempts to maximize their profit and their use of the resource. This is what is known as the "Tragedy of the Commons", a phrase made popular by Garrett Hardin in his article of the same name. In Hardin's explanation of the tragedy of the commons, each herder grazes the land to maximize their wealth. Even though it means that the grazing land will soon become useless, at least they maximized their wealth while it lasted. Some would argue that overexploitation and degradation of natural resource commons is bound to happen because users will maximize their utility of the resource at all possible costs (Hardin, 1968). However others believe that users can and should be responsible for the management of their resources, and that this will lead to better management (Ostrom, 1990, Wade, 1988, Baland and Platteau, 1996). These theories often apply to the consumption of a resource, such as fish or water available for irrigation, yet increasingly the problems with the natural resource commons apply to bodies of water that are being used as pollution 
sinks. This thesis explores the idea of applying these theories of collective action to remediate pollution.

Canada is viewed as a country with vast reserves of water resources, yet despite this wealth, water pollution is a problem in many of Canada's waterways. This puts the quality and quantity of drinking water available for the population in danger, perhaps in part due to the perception that Canadians have more water than they need. However, what is difficult for most Canadians to understand is that for a country with a large share of the world's freshwater resources, the actual amount of freshwater that is part of the hydrological cycle, i.e. the renewable water sources, is quite small. It is often stated that Canada has $20 \%$ of the world's water supply, however, this is deceiving (Sprague, 2007, 23). This $20 \%$ accounts for the water that is sitting in our lakes, rivers, streams and aquifers, and much of it is not renewable. The renewable water supply that Canada has is much smaller, $6.5 \%$ of the global supply (Sprague, 2007, 25), which still leaves Canada with the third largest renewable water supply in the world (it ranks behind only Brazil and Russia ${ }^{1}$ in terms of available freshwater (The Pacific Institute, 2006)). One additional point that should be noted is that much of the water in the rivers and streams flows north, away from the majority of the population that lives in the southern Canada. So while it is true that comparably Canadians have a lot of water, only $2.6 \%$ of Canada's freshwater is in the southern areas of the country, where the majority of the population lives

\footnotetext{
${ }^{1}$ This information was found in Table 1: Total Renewable Freshwater Supply, by Country, 2006 update. The total renewable freshwater supply includes both surface and groundwater. In addition, it should be noted that some of the information in this table is out of date. For example, the estimation of Canada's water supply is from 1985, Brazil is 2000 , and Russia is 1997.
} 
(Sprague, 2007, 25). Regardless of its abundance or scarcity, water pollution is a problem in Canada that not only affects the population but also has a detrimental effect on the ecosystem.

Some of the water pollution hotspots, according to Environment Canada, include the Fraser River, the St. Lawrence River and the Great Lakes basin (Environment Canada (f)). The Great Lakes basin, the largest freshwater body in the world has suffered from a long history of development, leaving pollutants such as sewage waste, mercury, and pesticides in its waters. Over 360 chemical compounds have been identified in the Great Lakes, wreaking havoc on the ecosystem. Public beaches are often closed in the summers and fish are found with tumours and lesions because of the poor quality of the water. With pollution problems facing Canada's freshwater, and given that this water is a common property, the question becomes, what is the best approach to take in order to restore the water resources in Canada?

The Hamilton Harbour is one example of an area that became severely polluted as a result of industry and municipalities releasing untreated effluent directly into the waters. It was transformed from a thriving port in the early 1800 s where fishing and recreation were main focuses of the harbour, to an industrial wasteland, with smokestacks taking over the visual landscape, and the wildlife disappearing. The harbour was not treated with the respect it deserved. However, since 1985 the harbour has also become an example of how a community can work together to create and maintain a remediation plan in an attempt to restore the harbour to its former glory. 
This thesis examines the case of the Hamilton Harbour, and the plan developed and monitored by the stakeholders, the businesses, educational institutions, recreation, community and environmental groups, as well as citizens at large. It examines the successes that the Hamilton Harbour RAP and its stakeholders have achieved in organizing a sustainable collective action group and the barriers to success that it faces, as they work towards reaching the goal of removing the Hamilton Harbour from the list of Great Lakes Areas of Concern (AOC) by the year 2015. Using the framework of Elinor Ostrom's design principles that in general characterize successful common-property institutions (this includes, this thesis will attempt to identify whether or not the Hamilton Harbour RAP has overcome some of the main challenges that Ostrom indicates are prevalent when managing common-pool resources. Ostrom's principles for successful common-property institutions include clearly defined boundaries (geographical and political), equitable benefits and costs, collective choice arrangements and organizations, monitoring (the resource and the rulebreakers), graduated sanctions for those who break the rules, conflict resolution mechanisms, and minimal recognition of rights to organize into a collective choice group by government. These design principles are often applied to situations where the local community consumes the resource such as irrigation systems, fisheries, and forestry (Ostrom, 2005, 259); they are not often applied to the case of the renewal of resources that have been degraded ${ }^{2}$, as is the case for the Hamilton Harbour. This thesis will show that the Hamilton Harbour RAP

\footnotetext{
${ }^{2}$ Note that this researcher was not able to find an example of where the design principles were applied to a polluted common pool resource.
} 
has been designed in a way that can foster success, based on Ostrom's principles. Her principles can be useful in outlining the challenges that a common property institution can encounter when remediating a polluted resource. Often the challenges that the Hamilton Harbour RAP has faced or is currently facing can be linked to the inability of the RAP to meet certain criteria that Ostrom indicates are important to a successful common property regime.

Hamilton Harbour was designated as an AOC under the 1978 Great Lakes Water Quality Agreement, which mandated the development of Remedial Action Plans (RAPs) for 42 identified Areas of Concern (AOCs) within the Great Lakes basin. The International Joint Commission (IJC) strongly encouraged the federal, and state/provincial governments in Canada and the United States to support the participation of communities in the development of these RAPs. Stakeholders for the Hamilton Harbour developed the RAP, and subsequently formed the Bay Area Restoration Council (BARC), a public advisory council representing the stakeholders. The goal of BARC is to monitor the health of the harbour and its watershed, monitor the RAP and to increase public awareness of the area. These stakeholders also formed the Bay Area Implementation Team (BAIT), a sub-group of stakeholders tasked with coordinating the implementation of the RAP. Most of the decision-making was completed when the RAP was established, i.e. it is the RAP itself that is a culmination of all the decisions that the stakeholders made. BARC and BAIT were then formed by the stakeholders in order to ensure that the RAP was carried out (see Table 1 for a diagram illustrating the organization of the Hamilton Harbour RAP). 
By understanding the successes that the Hamilton Harbour RAP, BARC, and BAIT have achieved and the barriers to success they face in implementing their mandates, other stakeholder groups can learn from what has arguably been one of the more successful RAPs in engaging the public in their local environment. The success of groups such as BARC in ensuring that the natural resource is restored to its initial state of health is important as water pollution becomes an increasing problem and as water becomes more scarce. The case of the Hamilton Harbour RAP is also important to the review of common property institutions, since much of the research to date has been on communities that consume the resource. This thesis adds to the body of work by Mark SprouleJones, who has researched the institutional design of the RAPs for the Great Lakes, in particular the Hamilton Harbour RAP as he was one of the original contributors to the RAP. Sproule-Jones focussed mainly on the role of the government in his analyses, and how government was affecting the ability of the stakeholders to operate. This thesis goes one step further and applies Ostrom's principles directly to the case study. Hamilton Harbour is a case where the resource has been used as a pollution sink. Although the end use of the resource is different (consuming vs. using as a sink) Ostrom's principles can still be applied to the Hamilton Harbour RAP. 
Table 1: Hamilton Harbour RAP Organization

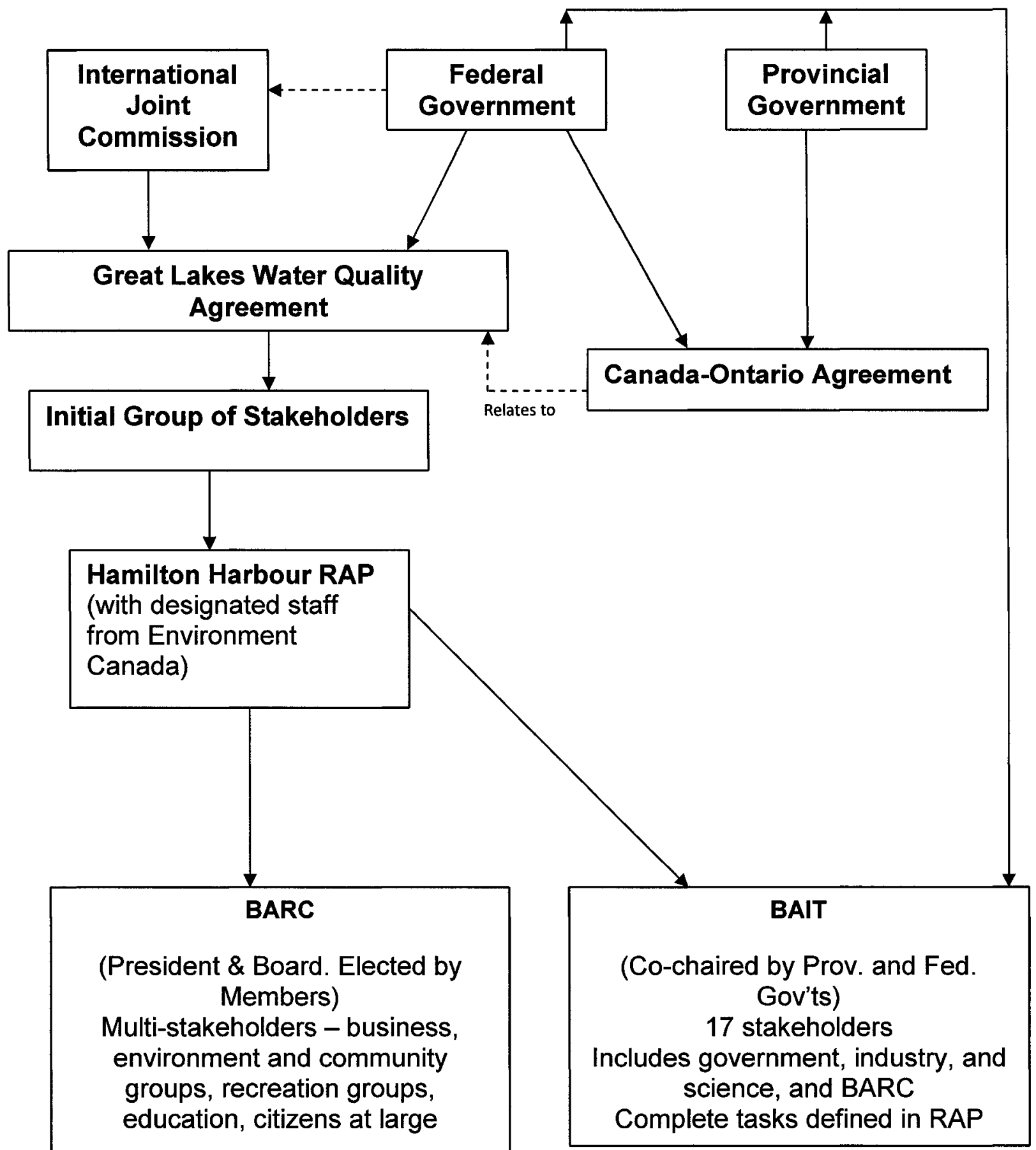




\subsection{Thesis Overview}

The purpose of this thesis is to examine the case of the Hamilton Harbour Remedial Action Plan and the stakeholder group that is responsible for overseeing the implementation of the remediation. The following chapters illustrate how Ostrom's principles for sustainable common property institutions can be applied to the Hamilton Harbour RAP and identifies the challenges that the RAP has encountered.

Chapter two outlines how the research was conducted for this thesis by examining the Hamilton Harbour RAP documentation. It also reviews documents that the organization has produced since its formation in 1994. This includes quarterly newsletters, annual reports, and annual progress reports for the RAP. By analyzing these documents, this thesis attempts to understand the progress the RAP has made as well as the challenges it has experienced, and how the stakeholders have adapted to overcome those challenges. The process used to conduct the interviews is also examined in this chapter, showing how it garnered additional information about the barriers to progress that this group faces. To help identify the successes and barriers BARC has encountered or is currently experiencing, this research incorporates information from interviews with former and current members of BARC and BARC partner organizations.

Chapter three examines the political environment in which the Hamilton Harbour RAP is situated. It discusses the role of various organizations in the development of the RAP such as the IJC, the federal government, as well as the provincial government. This chapter then outlines the formation of the 
Great Lakes Water Quality Agreement (GLWQA). The various pieces of legislation that govern pollution in the Great Lakes, from a Canadian perspective only are also detailed. It is important to understand the political environment under which the Hamilton Harbour RAP was established and under which it must operate in order to achieve the goals of cleaning up the harbour.

The fourth chapter outlines a brief history of the harbour, in particular the industrialization of the area, as well as the key users of the harbour itself. It also examines the formation of the community stakeholder groups that have been responsible for overseeing and implementing the RAP: the Bay Area Restoration Council (BARC) and the Bay Area Implementation Team (BAIT). In particular the discussion will focus on BARC, and examine the types of stakeholders involved in the organisation as well as the mandate. In addition, this chapter provides an outline of the relationships between BARC, BAIT, the stakeholders and the various government and government organizations.

Chapter five outlines the theoretical framework that is used to analyze the case study of the Hamilton Harbour RAP. This section presents Elinor Ostrom's seven key design principles to successful collective action, and supplement it with findings from other academics that have conducted research in the similar area. Evidence from the Hamilton Harbour RAP is then used to show how it meets or does not meet the principles. Analysing the Hamilton Harbour RAP and its stakeholder group, BARC, within Ostrom's framework reveals some of the challenges that the group may face and can establish to what extent the principles are satisfied or can be satisfied. This chapter also 
incorporates the analysis of BARC documents such as the TSH reports, the newsletters and the annual reports, as well as the information gathered from the interviews to examines the successes, and the challenges that the group or the RAP has faced.

Chapter six presents the conclusions of this paper. The analysis indicates that the Hamilton Harbour RAP is a good example of a collective action group that has followed the design principles that Ostrom has developed with varying levels of success. This chapter also outlines recommendations for the Hamilton Harbour RAP, based on this research. 


\section{Chapter 2 - Theory and Methods}

The purpose of this thesis is to evaluate how well the Hamilton Harbour RAP meets Ostrom's design principles for a successful common property resource (CPR) regime. In particular this thesis examines the challenges or barriers to success that the remediation of the harbour has encountered, and attempts to link these challenges to the inability of the RAP to meet some of her design principles. This is important because Ostrom has mainly looked at cases in which the resource was used for consumption; in the case of the Hamilton Harbour the purpose of the CPR regime is to remediate pollution, with the intent of making the resource useable for future generations. This chapter examines the theories behind the commons and collective resource management. It first discusses the commons, and the dilemma of the commons, and it also defines some of the key terms that are used in this thesis. The next section of this chapter briefly outlines Elinor Ostrom's key design principles for collective action in sustaining common pool resources. It is important to note that these principles are guidelines; they describe broad structural similarities in common pool resource management institutions, but each CPR is different and the institution that governs it needs to be tailored to each individual case. This chapter then outlines how I have conducted my research in order to evaluate this case study.

\subsection{The commons}

To understand the pollution management problems of the Hamilton Harbour, we need to start at the beginning - understanding the characteristics of the resource itself. This thesis attempts to do this by exploring the concept of 
the commons or common pool resources. Common pool resources are defined as "a national or man made resource system that is sufficiently large as to make it costly (but not impossible) to exclude potential beneficiaries from obtaining benefits from its use" (Ostrom, 1990, 30). This is the definition that is used for the remainder of this paper.

Common pool resources (CPR) can be further broken down, as Ostrom illustrates. She uses the term 'public goods' as synonymous with CPR. There are two main characteristics of public goods, as defined by Dolsak and Ostrom. The first is subtractability - what one person harvests from or deposits in a resource subtracts from the ability of others to do the same. The second main characteristic is that there is a cost of excluding potential users from the resource. This means that there is the possibility of a user to become a free rider, i.e. gaining from the benefits of the resource without bearing some of the costs of maintaining and regulating it (Dolsak and Ostrom, 2003, 7). For example, in the case of water, it is difficult to prevent others from using it, yet each of the uses, such as fishing, boating, etc. reduces the amount of clean water for others (Lovecraft, 2007, 221). It is a common argument in economics that public goods or CPRs should not be left to market forces. Rather, the government should step in to set regulations and to manage goods in order to ensure that the greater public can use them. A further division of CPR is to define multiple CPR, which can be defined as "resources that are used for different types of extractive and non-extractive purposes by different stakeholder groups and are managed under a mixture of property rights regimes" (Sneddon, 
$2002,728)$. This is particularly relevant to the case of the Hamilton Harbour, as it reflects some of the potentially conflicting uses that occur in that area.

\subsection{Stakeholders}

The term stakeholder is an extremely important one in the case of the Hamilton Harbour, and in the use of Ostrom's principles, although she generally uses the term participants. The definition of a stakeholder is fairly simple - it is member of a group of people of any size, organized or unorganized who share a common interest or stake in a particular issue or system; they are of various social and economic backgrounds, as well as from different scales from global to household (Grimble and Wellard, 1997, 176). A distinction between the rights to use the resource should also be included in the definition (Sproule-Jones, $2002,841)$, since this could determine which stakeholders have more rights and therefore a greater stake in the outcome of the collective action than others.

The definition can be further explored by examining the distinction between active and passive stakeholders: those that affect a decision (determine it) and those who are affected by a decision or action (Grimble and Wellard, 1997, 176). Agrawal and Gibson use this distinction to indicate that in regards to conservation issues, the multiple interests of the actors in a community should be examined in the context of how they influence decision making, and how internal and external institutions affect the decision-making process (Agrawal and Gibson, 1999, 630). For the remainder of this paper, the term stakeholder refers to the active stakeholders, unless otherwise specified. 


\subsection{Design Principles for Sustainable Collective Action Regimes}

One theorist in particular, Elinor Ostrom, has contributed to the large body of work on collective action, particularly in identifying characteristics of successful collective action groups. In her early work on collective action institutions, she stated, "What one can observe in the world is that neither the state nor the market is uniformly successful in enabling individuals to sustain long-term, productive use of natural resource systems" (Ostrom, 1990, 1). This underlines the importance that a new method of managing resources needed to be defined. Her work has since been expanded on and other theorists have added in their ideas to form various lists of what a collective action group would look like. Based on the argument that using resources needs to be sustainable, Ostrom's characteristics of sustainable resource management address the issue of sustainability as a responsibility of the community, and identifies that local-level solutions are important to achieving this goal (Leach, Mearns, and Scoones, 1999, 225). These characteristics have arisen out of the theory of Institutional Analysis Design (IAD), which uses

"concepts from economics, anthropology, law and political science, and (IAD) views all rules as incentive systems for individual and group behaviour rather than commands of a government or a leadership group. Rules can promote negative as well as positive consequences, and the rules for the Great Lakes have featured both kinds." (SprouleJones (b), 2002, 840).

Using IAD as her framework, Ostrom believes that collective action groups can be a successful way of managing common pool resources and has devised a list of characteristics, seven in general, with an eighth principle that is used in the larger and more complex cases (and in this paper will be grouped with another 
principle), that such a group should have in order to succeed. Please note that having a collective action group does not necessarily mean that the government is not involved. Ostrom indicates that the absence of government can have a detrimental effect on the process, and indicates that the government is necessary in many cases in order to ensure the long-term sustainability of the regime (Ostrom, 2005, 278). The following section will outline these principles and identify how the Hamilton Harbour meets or does not meet them.

The first design principle requires that the boundaries of the resource in question should be well defined in a couple of ways. The first is geographically, so for example if the resource in question is a forest, then it is very easy to physically define the area (Ostrom 1990, Baland and Platteau 2000, and Wade 1988). Baland and Platteau indicate that the resource boundaries itself should be small, in some cases the resource should even be fenced in (Baland and Platteau, 2000, 231). Dynamic resources, such as water, fish, and air, are difficult to define, making it more difficult to manage these resources. The second way is to define the users of the resource, i.e. those that have rights to the resource. Ostrom asserts that this approach addresses one of the problems of the commons, the free-rider problem, because the group can determine who or who is not a member. A free-rider is someone who uses a resource but does not shoulder the costs or responsibility of using it, leaving this to other users. A welldefined boundary limits access to the resource and allows participants to develop trust and reciprocity (Ostrom, 2005, 261). This is necessary in order to meet some of the remaining principles. 
For collective action to be successful there needs to be proportional equivalence between the benefits and costs of using the resource in a sustainable manner, the second of the design principles. Ostrom maintains that "When the rules related to the distribution of benefits are made broadly consistent with the distribution of costs, participants are more willing to pitch in to keep a resource well maintained and sustainable" (Ostrom, 2005, 263). An additional requirement, according to Singleton, is that the users need to prefer sustainable management to over-extracting all of the resource for their benefit (Singleton, 2000, 2). Participants in a collective action regime need to be aware of how reducing their consumption to a sustainable level will benefit them in the future; otherwise it becomes tempting to be a free rider. The benefits and costs can be examined financially (direct and indirect) as well as socially, in terms of improving the local environment for the use of the public.

A third requirement for a sustainable resource management system is that there is a collective choice arrangement. This collective choice arrangement should be open to all members of the public. This is important because the community itself often has knowledge of the resource, the economy, and the social dynamics of the area that government does not have, making their participation an important step in developing a sustainable resource management regime (Carr and Halvorsen, 2001, 108). This also means that the information needs to be communicated to the public in order to increase the credibility of the group. If information on the purpose of the project is not widespread, it decreases the public participation, which leads to a decrease in 
the legitimacy of the group (Baland and Platteau, 2000, 371). If a collective choice arrangement is organized well, it can be an integral tool in ensuring that the resource is managed sustainably.

The fourth design principle according to Ostrom is that the resource and its users need to be monitored. She states that, "Long surviving regimes select their own monitors who are accountable to the appropriators or are appropriators themselves and who keep an eye on resource conditions as well as on harvesting activities" (Ostrom 2005, 265). This self-selection serves two purposes. First, if the users themselves are responsible for monitoring the resource, they are more in tune with the state of the resource, and can therefore adjust the rules of using the resource when necessary, to accommodate sudden changes. The second purpose is that if those who use the resource monitor the harvesting activities (and the users), then each member may feel a greater sense of obligation to obey the rules, because if they don't, their fellow resource users might know that it was them who broke the rules.

Graduated sanctions, the fifth principle, mean that the first time a resource user misuses the resource, there is a punishment, but it is low in its severity and acts more as a warning than as a real punishment. It serves to warn other stakeholders about the penalties for breaking the rules (Ostrom, 2005, 267). The rules of the institution must be established in order for the graduated sanctions to work. This means, as Singleton points out, that users must know what actions are required in order to ensure the sustainability of the resource, and as a result, this information will allow them to develop appropriate management regulations 
(Singleton, 2000, 2). What is truly important about these rules is that "individuals who think a set of rules will be effective in producing higher joint benefits and that monitoring (including their own) will protect them against being a 'sucker' are willing to undertake conditional cooperation" (Ostrom, 1995, 267). All of the users need to know that the problem of free riders will be limited and their own rights will be protected. This increases the legitimacy to the group.

The sixth principle is for the group to have conflict resolution mechanisms in place. Ostrom indicates two key factors of this principle. The first is that there should be access to immediate and low cost local arenas to resolve conflict among users or between users and officials. The second is that there should be a higher level at which to resolve the conflict in order to avoid the capture of the mechanism by the local elite. One way to avoid conflict is to put mechanisms in place before the group even starts working together. For example, as Singleton points out, participants needs to know that the group is going to be in existence for an extended period of time, that the turnover in the relevant government agencies aiding the group is low, and that the "management agencies have enough independence from the larger political structures of which they are a part so that their commitments are credible" (Singleton, 2000, 5). By making the above points clear to the members of the group, there is less likelihood of conflict, especially between the group and the government.

The final principle that Ostrom indicates might not be in all collective action groups, but which is present in the case of the Hamilton Harbour, is the minimal recognition of rights. This means that the right of the group to organize 
is recognized by a national and/or local government. If the group was not formally recognized, a disgruntled member could complain to the government, and the government could impose its own regulations on the group (Ostrom, $2005,268)$. This recognition of legitimacy often comes in the form of legislation or a formal agreement. Having the state acknowledge the agreement also means that the state can aid in situations such as clarifying property rights, and providing a legal framework for enforcing those rights (Baland and Platteau, 2000,348 ). The rights of a group need to be recognized in order to have the participants buy in to the process. If participants think that the state can overrule the decisions they've made, it might make them less inclined to spend time and energy participating in this group.

\subsection{Reviewing Hamilton Harbour RAP literature}

To evaluate the Hamilton Harbour RAP and its stakeholder groups in the context of Elinor Ostrom's requirements for sustainable collective action for common-pool resources, a few methods of analysis are used in this thesis. The first is an examination and analysis of the documentation on the RAP such as the Stage 1 and Stage 2 RAP reports, as well as external documents that concern the Hamilton Harbour, in order to evaluate the Hamilton Harbour according to the seven main principles that Ostrom as identified as being essential to the development of a sustainable collective action approach to resource management. This thesis also proposes an eighth design principle specifically for resources that are polluted.

\subsection{Analysing BARC documentation}


The second methodological approach adopted in this research is an analysis of documentation produced by BARC. BARC, in its role as the public voice for the Hamilton Harbour, produces three types of reports on an annual and quarterly basis. The first report is the quarterly newsletter, entitled "Bringing Back the Bay", the first issue published in 1994. The purpose of the newsletter is to provide a venue for BARC to update the community on the progress of the work that BARC is doing, as well as on issues that affect the harbour. The newsletters often describe the progress of the programs that BARC has established and how these programs are affecting the harbour. In addition, the program educates people about the history of the harbour and the wildlife within the harbour. At the end of each newsletter, a few pages are devoted to an update from the RAP coordinator (an employee of Environment Canada). For the purpose of this thesis, I have looked at the fall editions of the newsletter. The reason for choosing the fall editions is that they are often a good summary of many events that have occurred during the year, especially the summer and spring, which are the busiest times of the year for the organization.

The second type of documentation that BARC produces each year is the annual "Toward Safe Harbours" report (TSH report). This report is based on the progress that the RAP has made in the previous year, and while it has evolved since the first publication, it generally focuses on one issue, such as non-point sources of pollution, the state of the beaches, wastewater treatment, etc. The report is produced by the BARC Monitoring Committee and each member of the committee has input into the report. Each report provides scientific research to 
back up the document and it explores what the goal was, what has been done, what is being done and what still needs to be done in order for that particular issue to be removed from list of impaired beneficial uses. This documentation was studied because it documents how the RAP goals are progressing as well as what kinds of barriers the group is facing. The first "Toward Safe Harbours" report was published in 1994 and all reports will be evaluated from 1994 to 2008 .

The third type of report that BARC produces each year is the BARC Annual Report. This is simply a report that outlines the finances of the group, as well as a summary of the activities that the group did during the year. The most interesting aspect of these reports is the financial statement. All of the reports have been examined in the following manner (Table 2):

Table 2: Analyzing BARC documents

\begin{tabular}{|l|l|l|l|}
\hline Question & Newsletters & TSH report & Annual report \\
\hline Main Focus/Content & $\mathrm{X}$ & $\mathrm{X}$ & \\
\hline Successes & $\mathrm{X}$ & $\mathrm{X}$ & $\mathrm{X}$ \\
\hline Challenges & $\mathrm{X}$ & $\mathrm{X}$ & $\mathrm{X}$ \\
\hline Tone & $\mathrm{X}$ & $\mathrm{X}$ & $\mathrm{X}$ \\
\hline Style & $\mathrm{X}$ & $\mathrm{X}$ & $\mathrm{X}$ \\
\hline Funding & & & $\mathrm{X}$ \\
\hline Changes in Corporate Strategy & & & $\mathrm{X}$ \\
\hline
\end{tabular}




\subsection{Interviews and questionnaires}

The third source to evaluate the RAP and BARC is personal interviews or questionnaires ${ }^{3}$ with previous and current members of BARC, members of key stakeholder groups, and a member of the IJC. The information garnered from these interviews provides further evidence of some of the challenges this organization has faced, and these challenges can be related to the inability of the Hamilton Harbour RAP to meet Ostrom's design principles. These interviews were started in October 2008 and were completed by December 2008. The purpose of the questionnaire was to learn about the successes and barriers to success in the Hamilton Harbour RAP from those who have worked closely with BARC and on the RAP, as well as to get some general information on how the group works. The list of possible respondents was largely compiled with the help of the staff at BARC, although a couple of participants were found based on their association with certain organizations or past research that had been done on the RAP. Because of the limited time that many of these participants have, I gave them three options with which to respond to the questionnaire: by e-mail, by phone, or in person. The responses were a mix between all three options. In total six people agreed to an interview by phone or in person and the remaining six chose to respond to the questions via e-mail. For those that chose to have an interview, the lengths of the interviews ranged from 20 minutes to just over an

\footnotetext{
${ }^{3}$ Please note that all of the interviewees and the names of the respondents to the questionnaire are confidential.
} 
hour. There were three types of questionnaires: the first was for a member of the IJC, the second was for current or past members of the BARC Board of Directors and the third was for members of organizations affiliated with BARC (i.e. BARC stakeholders). Each "type" of respondent had a different questionnaire because not all of the questions were applicable to each type of participant. The questionnaires are included in Appendices E, F, and G. The main purpose of these questionnaires was to gain an insight into what those associated with the group perceived the successes and barriers to success to be. The interviews were also useful to get a better understanding of how BARC itself worked, in terms of resolving conflicts and working with various levels of government, which will be helpful in the analysis of the RAP and BARC.

\subsection{Summary}

The ultimate goal of researching these documents and the interviews was to not only understand BARC but also to understand the stated and perceived challenges that the group faces. In addition, this information has been useful towards understanding BARC in the context of the main principles for a collective action group. By undertaking the above mentioned research, this thesis is better able to describe how this group works in terms of the key principles and ultimately what potentially could be done to improve how this organization functions. 


\section{Chapter 3 - Politics, Legislation, and Players}

This chapter provides a history on the legislation that established the Hamilton Harbour RAP, showing that public participation was a principle that the federal government adopted. By encouraging public participation, the government laid the groundwork for the ability of stakeholders to determine the plan to remediate the Area's of Concern (AOCs), especially for the Hamilton Harbour. In addition, this chapter outlines the legislation that governs the Hamilton Harbour. These rules were in place before the Hamilton Harbour RAP was established and determined how some stakeholders were legally required to abate their effluent releases. This chapter illustrates the role that government has played in the Hamilton Harbour RAP and the effect, as this thesis examines in later chapters, that government involvement has within a common property institution.

\subsection{It began with the International Joint Commission...}

Over 100 years ago, Canada and the United States signed the 1909 Boundary Waters Treaty, an agreement that was formed because the two countries share rivers and lakes. The actions of one country will invariably affect the other because of the mobility of water, and an agreement became necessary in order to resolve the potential disputes that might arise. The purpose of the treaty was to provide a mechanism to resolve disputes over the quantity and quality of waters that border the two countries (IJC (c)). To manage the treaty, the International Joint Commission (IJC) was formed, with equal representation from Canada and the United States. The commission has several roles, which 
include authorizing uses of water while protecting the rights and laws between the two countries, investigating water pollution, and recently they have expanded in to investigating air pollution for the two countries as the air pollution can have negative affects on not only the quality of the air but also on the quality of the water. One of the other responsibilities of the IJC is to monitor the water quality in the Great Lakes (IJC (c)). Several boards represent the different shared bodies of water; for the Great Lakes, there is the Council of Great Lakes Managers, the Great Lakes Science Advisory Board, and the Great Lakes Water Quality Board - the main role of these three organizations is to compile research on the ecosystem and water quality of the Great Lakes. The IJC initiated the Great Lakes remediation, by facilitating the development of the Great Lakes Water Quality Agreement.

The role of the IJC has been criticized because it has been argued that the group was not given a strong enough mandate by the two countries, and as a result, it does not have the authority to make binding decisions. For example, the IJC only has the authority to monitor situations and recommend actions. The IJC does not have any legal power. It can "sternly criticize" the Canadian and American governments for not making enough progress under the GLWQA, but it cannot do much more (Schiff and Winters, 2002, 9). In essence the IJC is relatively powerless (Sproule-Jones (a), 2002, 38). They may make recommendations but the two countries are not legally obligated to follow through on their implementation. 
The IJC is a strong proponent of the participation of communities, in particular in the development of the RAPs, as per the GLWQA. When the IJC was developing the GLWQA it engaged the public in consultation, using the expertise of those who lived in the basin to help develop the GLWQA, this set the stage for community involvement at the RAP stage, and increased support of the IJC and the GLWQA by the public (Botts and Muldoon, 2005, 40). Many believe that this support by the community has made it difficult for the Canadian and American governments to ignore their obligations under the GLWQA (Botts and Muldoon, 2005, 41). It should be noted that the IJC, while at first actively engaged the public, began to decrease its public dissemination of information in the 1990s, effectively undermining the public involvement and putting in jeopardy the political will that is necessary to keep the governments committed to the GLWQA (Botts and Muldoon, 2005, 209). The role of the IJC has primarily been an advisory role, but the decrease in public participation is a concern, given that the goals of the GLWQA are long-term. This thesis does not explore this issue further, but this lack of legal power to enforce the GLWQA means that governments are not legally committed and as a result can shirk their responsibilities. This has implications for the Hamilton Harbour, as is examined in further chapters.

\subsection{The Great Lakes Water Quality Agreement}

\subsection{GLWQA: a history}

One of the key achievements of the IJC was the development of the Great Lakes Water Quality Agreement (GLWQA). The toll that pollution was taking on 
the Great Lakes started to become a major concern the 1960s. It became clear that the human effect on water was heading towards dangerous levels and that plans needed to be implemented quickly in order to avert disaster. A major sign of the deteriorating health of the Great Lakes was the eutrophication ${ }^{4}$ of Lake Erie, one of the key causes being the increased levels of phosphorus from untreated sewage that was released directly into the lake, mainly in the United States. According to Botts and Muldoon, sewage treatment plants were woefully inadequate in the U.S., compared to Canada, and this would be an expensive undertaking for the U.S. (Botts and Muldoon, 2005, 15). Between 1972 and 1978 the U.S. spent $\$ 10$ (US) billion on upgrades (Sproule-Jones, 2002, 41). The 1972 agreement had an extremely positive effect on Lake Erie, with noticeable declines in phosphorous levels between 1972 and 1978.

In 1978, the GLWQA was revised and expanded, with a new mandate to "restore and maintain the chemical, physical and biological integrity of the Great Lakes Basin Ecosystem" (Government of Canada). The 1978 agreement focused more on toxic substances in the water and sediment, as research indicated the increasing presence of toxic chemicals in all of the lakes and its tributaries. This new agreement took more of an ecosystem-based ${ }^{5}$ approach than the initial agreement. In order to restore the Great Lakes, the whole Great Lakes Basin needed to be included in the plan to not only clean the water but

\footnotetext{
${ }^{4}$ Eutrophication is primarily caused by excess phosphorous (mainly from fertilizer). This phosphorous encourages plant growth in the water, which consequently decreases the oxygen in the water and leads to fish kills and signals reductions in biodiversity. Lake Erie became known as the dead lake. (Environment Canada, 2001)

${ }^{5}$ An ecosystem approach means considering interacting components of air, land, water and living organisms, including humans, within the drainage basin of the St. Lawrence River at or upstream from the point at which this river becomes the international boundary between Canada and the United States (Government of Canada).
} 
also eliminate the discharge of toxic substances (Botts and Muldoon, 1996). The main provisions and goals of this agreement included the developing water quality standards, monitoring water quality, decreasing pollution from municipal sources, in particular from sewage and wastewater treatment plants, and decreasing pollution from industrial sources (IJC (a)). It was also in this agreement that the Areas of Concern (AOCs) were first mentioned, however just in general terms, indicating that these areas are toxic and should be eliminated (IJC (a)). It took until 1987 for these AOCs to be defined, and identified, in part because of the lack of knowledge about the severity and types of pollution in the lake at the time that the 1978 agreement was signed.

\subsection{GLWQA: Area's of Concern}

In 1987, once more extensive research was conducted on water quality in the basin the 1978 agreement was revised to include a more detailed outline for the remediation of the Great Lakes and a better definition of the AOCs. These AOCs were identified as the most toxic and contaminated sites in the Great Lakes Basin, based on a set of criteria that indicated impairment of beneficial uses as a result of changes in the physical, chemical or biological integrity of the water (for a complete list of these uses see Appendix A). Based on these criteria, 43 (later 44 ) sites were identified, and they were classified into two categories: Class A and Class B. Class A AOCs were areas where there was significant environmental degradation and the impairment of beneficial uses was severe (Bixby, 1985, 10). Seven of these Class A AOCs were located in the U.S. and five were in the connecting channels between the two countries. Only 
one was located entirely in Canada, that being the Hamilton Harbour (Bixby, 1985, 11). Class B AOCs were less severe, and action, while urgent, was not nearly as urgent as the more toxic regions in the Great Lakes. The list of impaired beneficial uses generally include things such as the effect of water quality on wildlife, the beaches, effect of water quality on the drinking water, and the aesthetic effect of pollution. Sproule-Jones has suggested that the development and identification of these impaired uses was not sufficient and has since caused further conflict amongst stakeholders. The list did not include all possible uses of the water, omitting the consideration of swimming, recreational boating, or shipping (Sproule-Jones (a), 2002, 45). This could create a problem if restoring the natural habitat of the area meant that areas accessible by boat would be diminished. If this kind of conflict about the uses of the water did arise, it was in the stages of developing a Remedial Action Plan (RAP).

\subsection{GLWQA: Remedial Action Plans}

The main tool for restoring the Great Lakes defined in the GLWQA was the Remedial Action Plan (RAP). Each RAP was required to include a variety of items, most importantly the identification of the environmental problems in the AOC, the causes, and the plan for their remediation (IJC (a)). For a detailed statement of what each RAP was to include, see Appendix B. In the case of the Hamilton Harbour, the RAP was developed based on several primary and secondary principles. The primary principles included following the ecosystem approach but the stakeholders also agreed to consider that the "economic, social, and environmental goals must be viewed in an integrated manner, that not 
one of the three can or should take precedence over another" (Rodgers et al, $1988,25)$. The other primary principle was 'zero discharge'; a philosophy adopted to ensure that all toxic emission effluents into the water be virtually eliminated. There are also some secondary principles, which include a focus on human health and the need for public acceptance and support of the remedial actions. In addition, they agreed that the aesthetics should be improved, including better public access to the harbour.

Another main principle of the RAP is that it follows the practice of adaptive management. Hall and colleagues define adaptive management as "a systematic process for continually improving management policies and practices from the outcomes of operational programs (Hall, O'Connor, and Ranier, 2006, 10). The group uses the updated information they receive from monitoring in order to change the plans and actions if need be. The Hall report also indicates that the RAP follows its principle of ecosystem management by incorporating interdisciplinary integration, i.e. the collaboration between different agencies to monitor and modify remedial actions (Hall, O'Connor, and Ranier, 2006, 11). This is important as ecological situations change over time so the process needs to be flexible to meet those challenges.

There are three stages to the RAPs: identifying the problems, identifying the goals and confirming that the goals have been met (see Table 3). The most difficult stage is Stage 2, which is the stage at which many of the RAPs are today. Only three AOCs have achieved Stage 3: Collingwood Harbour ON, Severn Sound, ON, and Oswego River/Harbour, New York (Environment Canada 
(c)). An area can be delisted as an AOC once the criteria for the RAP have been

met. The decision to delist the $A O C$ is a joint decision by the federal

governments, regional governments, and RAP participants, with advice from the

IJC (Environment Canada (c)). The decision on whether or not an AOC can be

delisted is made even more complicated by the fact that it is difficult to determine

the success of remediation. The IJC itself has stated that is it often challenging

to determine the status of the restoration efforts, in part because of the difficulty

of maintaining monitoring data (IJC (b)). The importance of monitoring is

explored further in chapter 5 .

Table 3: Stages of the Remedial Action Plans

\begin{tabular}{|l|l|l|}
\hline Stage & Title of Stage & $\begin{array}{l}\text { Brief Description of } \\
\text { Stage }\end{array}$ \\
\hline Stage 1 & $\begin{array}{l}\text { Environmental conditions } \\
\text { and problem definition }\end{array}$ & $\begin{array}{l}\text { This stage outlines the } \\
\text { starting point for the Area } \\
\text { of Concern and identifies } \\
\text { local Beneficial Use } \\
\text { Impairments }\end{array}$ \\
\hline Stage 2 & $\begin{array}{l}\text { Goals, Options, and } \\
\text { recommendations }\end{array}$ & $\begin{array}{l}\text { This stage defines the } \\
\text { remedial actions to clean } \\
\text { up the AOC }\end{array}$ \\
\hline Stage 3 & $\begin{array}{l}\text { Evaluation of remedial } \\
\text { measure and confirmation } \\
\text { of restoration of uses }\end{array}$ & $\begin{array}{l}\text { This stage allows for the } \\
\text { designation of an AOC to } \\
\text { be removed once the } \\
\text { beneficial uses are } \\
\text { shown to be restored. }\end{array}$ \\
\hline
\end{tabular}

Source: Hall, O'Conner and Rainer, 2006, 3

Once the AOC has been delisted, the work should not end, as the water quality needs to be maintained. This has been recognized by the governments ((Environment Canada (c)). The work that needs to go into the development of a RAP is quite extensive. Monitoring and research are the two most important steps in the initial development of the RAP, and continued monitoring allows 
governments and communities alike to evaluate how much improvement has been made in the RAPs and how much more work needs to be done.

\subsection{GLWQA: Lakewide Management Plans}

The GLWQA also includes a provision for a Lakewide Management Plan (LaMPs) for each Great Lake, which are plans that relate to the water quality in the open waters of the Great Lakes. The purpose of these plans is to "assess, restore, protect, and monitor" (Environment Canada (f)). This is in line with the ecosystem approach to Great Lakes management. Some claim that LaMPs are more useful than RAPs because

"efforts toward cleaning the lakes are more likely to be successful if they deal with the lakes as whole bodies rather than as a series of discrete problems. In this sense, addressing the localized problems found in Areas of Concern by completing and implementing RAPs for those AOCs can be seen as desirable, but less so than developing LaMPs." (Inscho and Durfee, 1995, 62).

However, provincial officials believed that the RAPs should come first. Arguing that it was an issue of resources, officials indicated that the RAPs should be focused on first, before "shifting resources to new and potentially more difficult undertakings" (Inscho, 1995, 63). It is not clear with this research which of the two, the LaMPs or the RAPs, have become the larger focus of the governments. What is clear is that with both of these approaches, public participation is important, although it has manifested itself much more in the RAPs than in the LaMPs. This author contends that the RAPs are more important because they are connected to a specific location; it is easier to build public support for the plans, whereas LaMPs, because they apply to each Great Lake as a whole, are 
easier to ignore, because it is more difficult for the public to see how they are connected to the open waters of the lakes. The RAPs target areas that are heavy in pollution, typically where industry and large municipalities are located. If these areas are restored, then the open water of the lakes will be much healthier.

\subsection{GLWQA: Public participation}

The GLWQA indicated that the public should be included in the formation and implementation of the RAPs. However it does not specify to what degree, stating only that the parties should ensure that the public is consulted in all actions undertaken (IJC (a)). Both Canada and the U.S. heeded this suggestion, and encouraged the formation of citizen advisory councils (CACs), who would draft and in some cases monitor the RAPs and their progress. Instructions issued by the Ontario and Canadian environmental ministers in the fall of 1992, calling for more citizen participation suggest that this is an important, ongoing issue within the federal and provincial administrative communities (Inscho, 1995, 65). It should be noted, however, that the province does not have an obligation for public involvement, while the federal government does, as per the GLWQA. This can be seen further on in the analysis of the Hamilton Harbour RAP, and the funding that the CAC receives from the federal government as compared to the provincial government.

\subsection{GLWQA: Role of states and provinces}

The GLWQA is only an agreement between the Canadian and American governments at the federal level. While this was a big step towards recognizing that the two countries needed to cooperate in rejuvenating their shared water 
resources, the agreement itself was not signed by arguably the more important players: the state and provincial governments. The state and provincial governments were implicated in the agreement, and were involved in identifying AOCs (IJC (a)), but they were not signatories of the agreement. It is interesting that they were never more involved in negotiating the agreement, due to the fact that in both countries the state and provincial governments have constitutional control over environmental policy. The federal governments still develop nationwide policies. The states and provinces are responsible for deciding how to meet those policies and are able to set their own policies. As a result, the provinces and states that bordered the Great Lakes developed and signed their own agreement: the Great Lakes Charter.

\subsection{The Great Lakes Charter}

The Great Lakes Charter was signed in 1985 by the governments of Ontario, Quebec, Illinois, Indiana, Michigan, Ohio, New York, Minnesota, Pennsylvania, and Wisconsin. It has been called " a unique bilateral effort to clean up the Great Lakes basin at the sub national level" (Sproule-Jones (a), 2002, 44). The charter was a non-binding agreement that set out five key principles of management of the Great Lakes. They are as follows:

a) Integrity of the Great Lakes basin;

b) Cooperation among jurisdictions;

c) Protection of the water resources of the Great Lakes;

d) Prior notice and consultation; and

d) Cooperative programs and practices. (Environment Canada (e))

In 2001 there was a Great Lakes Charter annex that further committed the premiers and governors of the member provinces and states to cooperating in 
the management of the lakes that related not only to the surface water but also to the ground water. As per the Environment Canada website that outlines this agreement, provinces and states now have the responsibility to develop legislation that protects the Great Lakes Water basin, yet much of the focus is on water diversion, not on decreasing the pollution of these resources. This agreement between the states and provinces is important as it symbolizes that, in principle, they are committed to restoring and maintaining the integrity of the Great Lakes basin, however it is not enough to commit the provincial government to GLWQA.

\subsection{The Canada-Ontario Agreement}

The connection between the province and the GLWQA comes in the form of a third agreement that covers the Great Lakes: the Canada-Ontario Agreement (COA). The national and provincial governments have been working together since 1971 on the COA and have since renewed the agreement four times, the latest renewal in 2007. The main purpose of this agreement is for the federal and provincial governments to cooperate and coordinate their efforts to take care of the Great Lakes. The agreement is guided by the vision of a "healthy, prosperous and sustainable Great Lakes Basin Ecosystem for present and future generations." (Environment Canada (b)). Various principles are listed in the agreement, including sustainability (social, economic and environmental), taking an ecosystem approach, and encouraging public and stakeholder participation. The main goals of the agreement are related to following through on commitments made to the AOCs and their RAPs, decreasing pollution in the 
lakes, providing resources to municipalities to improve their sewage treatment programs, management strategies for contaminated sediment, increasing knowledge of pollutants in the water (sources, effects, etc) as well as virtual elimination of persistent bio-accumulative toxic substances as well as reducing other harmful pollutants in the water. This plan also calls for renewed commitment to the Lakewide Management Plans under the GLWQA.

This agreement outlines the responsibilities of both the federal and provincial governments in relation to their commitments to the GLWQA. Since the GLWQA is a federal obligation, and the environment is a provincial responsibility, there needed to be some sort agreement between the two levels of government in order to have a consistent plan to remediate the Great Lakes. This allowed for financial and technical support to be shared amongst the two governments. It was also an agreement that provided a large degree of harmony between the goals of the federal and provincial governments with respect to the Great Lakes (Botts and Muldoon, 1996, 33). Because of the fact that environment was under the jurisdiction of the provincial government, and that many of the sources of pollution in the Great Lakes are land based, Ontario was liable for much of the expense, and thus welcomed the COA as a way to share costs with the federal government (Botts and Muldoon, 1996, Inscho and Durfee, 1995). Some provincial officials interviewed by Inscho and Durfee in the early 90 s expressed a concern that active involvement in a Great Lakes' clean-up could be a financial burden for the province, giving it responsibilities for which it did not have sufficient funds (Inscho and Durfee, 1995). The federal government 
did provide funding to the province of Ontario, such as a loan program to assist the province in paying for such infrastructure construction in 1971, and $\$ 65$ billion over three years in 1982. Unfortunately, the government withdrew itself from funding municipal infrastructure projects, an area in which a significant amount of work needed to be done, in the late 80 s (Inscho and Durfee 1995). The development of the COA is important but it should be noted that like all of the agreements discussed above, it is simply an agreement with no legislative powers. This means that it is possible that the COA can be used to maintain the status quo of environmental protection in the Great Lakes, a point that will be discussed further on in this paper.

Public participation was also outlined in the COA as an important component in the remediation of the resource. The 2002 COA has a provision for public participation, indicating that public and stakeholder viewpoints are considered in the decision making process and that they are able to actively be engaged in activities that support the agreement (Environment Canada (b)). In addition, RAP Public Advisory Councils are identified as being "essential" to achieving plan implementation (Inscho and Durfee, 1995, 68). To preserve their participation, Canada and Ontario agreed to "sustain public involvement and advisory programs for the implementation phase of RAPs" (Inscho and Durfee, $1995,68)$. This is a promise that has certainly been kept by the federal government, at least in the case of the Hamilton Harbour. The recognition of public advisory councils is a positive step in moving towards a more holistic management vision for the Great Lakes. 


\subsection{Pollution legislation in Canada and Ontario}

When pollution was recognized as a major problem, not only in the Great Lakes, but also in the environment in general, the federal and provincial governments started to develop legislation to deal with this problem before and during the time that the GLWQA was developed. At the federal level, the major policy that deals with pollution in Canada is the Canadian Environmental Protection Act (CEPA), which was first proclaimed as an act in 1988. It was revised in 1999, according to Environment Canada, with the goal to "prevent pollution and protect environmental and human health" (Environment Canada (a)). The government lists several key principles under which the act operates; one of those being the polluter pays principle. This means that the "producers and users of harmful substances, pollutants and wastes have a responsibility for bearing the costs associated with the safe use and disposal of these substances and wastes" (Environment Canada (a)). There is a mandate for enforcement under CEPA. The first step in this process, according to the CEPA registry on the Environment Canada website, is that there is a site visit and inspection. The act allows the government to issue tickets for offences and collect data on emissions ${ }^{6}$ among other methods before the offending company is sent to court for violations. This means that the industries that are within the Great Lakes Basin, on the Canadian side, are obligated under CEPA to abide by the law. Despite this, CEPA is not nearly as important as the provincial legislation.

\footnotetext{
${ }^{6}$ This is done under the authority of the National Pollutant Release Inventory (NPRI). Companies are required to report the release of pollutants if the company is a certain size and if the pollutants are over the minimal allowable threshold (Environment Canada, CEPA)
} 
Another piece of federal legislation is the Canada Water Act, first passed

in 1970. The goal of this act was to

"provide for the management of the water resources of Canada, including research and the planning and implementation of programs relating to the conservation, development, and utilization of water resources" (Department of Justice).

It recognizes that increasing demands are being placed on Canada's water resources and that pollution is threatening not only the environment but also the health of Canadians. The importance of this agreement lies in the fact that it requires the federal and provincial governments to work together to establish a water management plan.

The key piece of environmental legislation in Ontario ${ }^{7}$ is the Ontario Environmental Protection Act (EPA). One important premise of this act is that anyone is prohibited from discharging a contaminant into the natural environment that causes or is likely to cause an adverse effect (Ontario Ministry of the Environment (b)). All companies in Ontario that obtain new equipment or make modifications to their existing equipment, equipment that has the potential to release substances that are or may be harmful to the environment, must be registered on the Certificate of Approval (CoA) process (Ontario Ministry of the Environment (a)). Once this CoA has been submitted, the Ontario Ministry of the Environment (MOE) reviews the application, and investigates the potential effects that this might have on the environment.

\footnotetext{
${ }^{7}$ Please note that this paper will only discuss Ontario legislation because it is more relevant to the Hamilton Harbour. The province of Quebec also has environmental legislation, which would govern the St. Lawrence Seaway, one of the AOCs.
} 
Another regulation that was developed in 1987, around the time that the RAPs were established, was the Municipal/Industrial Strategy for Abatement (MISA). This legislation played a key role in the remediation of the Great Lakes. According to the MOE, MISA was its response to the increasing levels of toxic substances entering Canada's waterways (Ontario Ministry of the Environment (c)). MISA covered nine major industries that release large levels of persistent toxic substances directly into the waterways, the most relevant to the Hamilton Harbour being the steel industry and municipal sewage treatment plants. Some of the key provisions under MISA included:

- For every chemical parameter in the MISA regulations there are: two limits: daily (i.e., not to exceed value on any day) and monthly average

- A required monitoring frequency to demonstrate compliance with the limits

- Every effluent must not be toxic to fish and water fleas

- Each plant must prepare an annual report to be available to the public

- Each plant must submit summary quarterly reports to the ministry

- Incidents of non-compliance must be reported directly to the ministry followed by a letter. (Ontario Ministry of the Environment (c))

There are other pieces of legislation that while they play a smaller role, do govern the Great Lakes in Ontario. One of these acts is the Ontario Water Resources Act (OWRA), which was first established in 1990, and covers pollution emissions. The purpose of this act is to protect Ontario waterways and to promote their sustainable use - this includes surface water as well as groundwater. In addition, there is the federal Fisheries Act of 1868 that prohibits the deposit of "deleterious" substances into water frequented by fish", however, as Sproule-Jones points out, this act has not been used for pollution abatement in the Hamilton Harbour (Sproule-Jones, 1985, 20). An additional act that covers the Hamilton Harbour is the Navigable Waters Protection Act that guards against 
uses of harbour land and water that could inhibit shipping. Both the federal and provincial governments play an important role in governing the waters of the Great Lakes and consequently, the Hamilton Harbour. However some argue that despite the fact that the federal government has jurisdiction in the basin it prefers not to use its more limited constitutional and statutory powers for pollution abatement (Sproule-Jones, 1985, 21). The one exception is when it involves vessel pollution strictly regulated by the Hamilton Harbour Commissioners (Sproule-Jones, 1985, 21). 'Navigating the waters' of pollution legislation can be difficult in Canada, however, it is clear that while the federal government has some obligations for pollution regulation, the provincial governments have more authority. Of the acts mentioned above, MISA, the Certificates of Approvals, and the OWRA are the most relevant to the Hamilton Harbour. They have had a direct effect on forcing municipal governments and industry to reduced their emissions in the Hamilton Harbour.

\subsection{Summary}

The purpose of this chapter was to introduce the key agreements and pieces of legislation that govern the Great Lakes, specifically the key acts that govern the Hamilton Harbour. The first half of this chapter outlined the Great lakes Water Quality Agreement, which is the basis of the AOCs and the RAPs. The most important point to take away from this information is that, in addition to defining the areas that were most in danger, it also identified the importance of community participation in not only defining the RAPs but also in implementing them. This inclusion of the community was very important in the development of 
the Hamilton Harbour RAP, as the remainder of this thesis will emphasize. This approach to renewing the Great Lakes was a new stage in how the government dealt with the public. The Canadian government allowed the participants to become actively engaged in the process, a decision that this thesis shows has been beneficial to the remediation of the Hamilton Harbour.

The second section of this chapter was devoted to outlining the key pieces of legislation or the "rules", as Ostrom would identify them, which affected the waters of the Great Lakes. This underlines the idea that there are different jurisdictions in not only the Hamilton Harbour but also the Great Lakes in general. As a result, it can be confusing as to which level of government is responsible for what. This section attempts to clarify these responsibilities. There are those who are critical of the roles that the two levels of government play. For example, some argue that there is lack of clarity of jurisdictional responsibility for environmental matters; that the two levels of government often avoid coercive regulations, especially those that would harm economic development in favour of environmental quality; and third, there is a lack of a well-established mechanism to facilitate intergovernmental consultation (Johns and Rasmussen, 2008, 85). The fear is that the respective levels of government will "pass the buck" and not follow through on their obligations to the environment, as per the regulations. Governments tend to make more popular decisions for which they claim credit. But, as Johns and Rasmussen claim, "blame-avoidance generally prevails, with federal officials reluctant to offend provincial independence and provincial authorities reluctant to do anything that might disturb established patterns or 
relationships" (Johns and Rasmussen, 2008, 85). This is a great concern, because if neither level of government forces the kind of change that is needed in order to discourage pollution, then the problem might still persist. This is why the community participation is so important, because it acts as the extra voice that no longer accepts this kind of policy. If communities are tasked with the responsibility of their own resource, they will in kind build the political will for governments to ensure that the guidelines for pollution are enforced. The following chapter will describe the Hamilton Harbour, and the community that is involved in protecting it. 


\section{Chapter 4 - Hamilton Harbour and its caretakers}

The purpose of this chapter is to provide a background for why the Hamilton Harbour was identified as an AOC, and why it is important for the Hamilton Harbour RAP to be successful. The second half of this chapter introduces the stakeholders via their participation in BARC and BAIT. This chapter outlines the purpose behind the two organizations and then compares the role that each plays. Of particular interest is to understand why these groups were separated and the impact that this separation has on the ability of the Hamilton Harbour RAP to meet Ostrom's design principles.

\subsection{Hamilton Harbour: A brief history}

Burlington Bay, more commonly known as the Hamilton Harbour is a 2150 hectare embayment at the western end of Lake Ontario (Hall, O'Connor, and Ranier, 2006, 2). The cities of Hamilton, and Burlington are on its border with populations of over 500,000 , and 164,000 respectively (Statistics Canada). Once a beautiful area that was the center of both of the communities, it is now tarnished with a reputation as an extremely polluted body of water. Smoke stacks and factories dominate the landscape on the southern shore of the harbour. It is hard to see past the southern shore of the harbour to the beauty of the remainder of the bay. There are still areas of the harbour that are beautiful, lush with wildlife and recovering marshes. The Hamilton Harbour didn't always have such a bad reputation. It used to be a thriving area, and thanks to remediation efforts, is starting to become one again. 
The Hamilton Harbour once had a thriving fishing industry and was the hub of recreational activities year round for the surrounding communities. Development in the bay started over 200 years ago, and at that time, it was still possible to fish the waters. However in the 1900 s industry and residential uses of the water began to expand contributing to the deteriorating water quality. There are and have been a variety of uses of the harbour for a variety of different types of users. In the 1890s, "The favourite playground of Hamiltonians was Burlington Bay" (Evans, 1970, 170). The area was popular with city inhabitants for fishing, swimming and picnicking. Boat cruises were also popular at the time, with the local population and tourists taking advantage of the amenities near the water. In the winter, skating, and ice fishing were popular pastimes on the frozen waters of the harbour. While the harbour still remains an area with multiple recreation opportunities, it is not to the extent as it was in near the turn of the $20^{\text {th }}$ century.

\subsection{Land and water use}

Industrialization in the area began to take hold at the turn of the $20^{\text {th }}$ century. The main industry located around the harbour was at the time, and still is the steel manufacturing industry. Two factors contributed to the arrival of what has become the backbone to Hamilton: the first was the introduction of protective tariffs in the 1870 s to encourage the growth of the Canadian steel industry and the second was the development of the Welland Canal in the 1880s which enabled manufacturers to ship their products via the Great Lakes, to the rapidly expanding Western Canada (Evans, 1970, 177). The steel industry has had a 
large impact on the local economy. In addition to making the Hamilton Harbour a major hub for steel production in Canada, all manufacturing activity increased in the area, with the manufacturing industry annually contributing to approximately $4 \%$ of Ontario's GDP or $\$ 12$ billion in 2006 (Hamilton Economic Development (b)). This had lead to the harbour becoming a major shipping port, and in 2004 the harbour shipped $25 \%$ of the 45 million tonnes of cargo transit in the St. Lawrence Seaway (Hamilton Economic Development (b)).

The affect that industrialization had on the landscape is very clear when comparing a map of the harbour in1835 to a map of the harbour at the time of the development of the RAP in 1992 (See Appendix C and D). In 1835 the City of Hamilton was barely encroaching on the harbour, but in the 1989 map, it is clear that development and industry have made a large impact on the landscape. Industry began to infill some areas of the harbour, which changed the landscape dramatically, eliminating $75 \%$ of the wetlands and filling in $25 \%$ of the shoreline (Environment Canada (h). At the time that the RAP was developed, the Canadian National Railyards were located on the west corner of the harbour while the steel manufacturing operations of Stelco and Dofasco as well as many other industrial operations including Firestone, International Harvester, Proctor and Gamble, and Westinghouse were situated on the southern shore (Bixby, 1985, 14). At the start of the remediation process, in 1985, the land use on the shoreline of the harbour could be broken down as follows:

Industrial, including proposed industrial on existing piers $52 \%$

Transportation $15 \%$

Residential $11 \%$

Institutional (cemeteries, public buildings) 10\% 
Uncommitted 5\%

Private open space (including marines and golf course) $5 \%$

Public Open Space (including Marina and park) 2\% (Sproule-Jones, 1985, 4)

The lack of public open space is particularly revealing, as it prevented the community from feeling connected to the harbour. The harbour was no longer a gathering area for the residents of the two cities; rather it became a source of shame. There were positive aspects to the development, that being that in the 1930s the Royal Botanical Gardens were developed, transforming abandoned gravel pits into a natural retreat around Cootes Paradise and Dundas valley (Evans, 1970, 210). However, at the time that the RAP was developed, it was clear that the encroachment of industry and residential properties on the shoreline were affecting the health of the harbour.

\subsection{Fisheries}

It is difficult to believe that the Hamilton Harbour once supported a healthy commercial fishing industry, however this was indeed the case at the turn of the $20^{\text {th }}$ century. As Rodgers et al indicate the Hamilton Harbour was a very important fish habitat in western lake Ontario in the 1800 s. The variety of fish available there included the coldwater fish such as lake trout, whitefish, and lake herring. The commercial catch in the late 1800's represented 48 percent of the western lake fishery and make up 15 percent of Lake Ontario's total commercial catch (Rodgers et al, 1988, 113). By 1900 the water quality was deteriorating and the fish population responded in kind. Commercial catches of the coldwater fisheries that included species such as lake trout, whitefish and herring peaked at 
$4,500,13,600$, and $114,000 \mathrm{~kg}$ per year in the late 1800 s and declined to 0,181 and $68 \mathrm{~kg}$ respectively by 1950 (Rodgers et al, 1988, 114). Pollution was one of the major causes of this decline. There were reports of dead fish and spawning beds in close proximity to industrial discharges (Rodgers et all, 1988, 114). In addition to pollution, habitat destruction was another major contributor to the decline in the fish population; about $75 \%$ of the marshlands (and fish spawning grounds) have disappeared in the past 150 years (McMaster University). Other factors such as competition from invasive species, many of which were transported on the numerous shipping vessels that enter port each year and over fishing also became a problem, also affected the fish populations.

A similar collapse happened with the warm water fishery, shortly after the decline of the coldwater fisheries. The species affected by this collapse include the bluegill, the brown bullhead and white perch. Recreational fishing was also a popular pastime, and at one point supplemented the diets of local residents, however, in 1949 fishing was banned (McMaster University). While commercial fishing itself no longer seems to be a viable option for the harbour, the improvement of the water could bring a return to sport fishing in the harbour, and of course, an improvement in the natural habitat. Not only would the resurgence of fish and their habitat be beneficial to the harbour, but it also has the potential to be beneficial to the rest of the lake, which as mentioned in the previous chapter, is why it is important to have the LaMPs and the RAPs. Based on the literature reviewed, it is not clear if the Hamilton Harbour RAP considered the 
effects that their remediation efforts would have on the fish population at the lake-wide level - their primary concern is the harbour and its watershed.

\subsection{Pollutants}

As mentioned above, pollution has had a large impact on the Hamilton Harbour. When the Hamilton Harbour was listed as an AOC, the IJC and its Great Lakes Water Quality Board listed the following reasons:

Conventional Pollutants ${ }^{8}$

Heavy metals

Toxic Organics in Fish

Contaminated Sediments

Eutrophication

Fish Consumption Advisories

Aesthetics (Hamilton Harbour Remedial Action Plan Writing Team, 1992, 1)

The sources of pollution in the harbour can be divided into point and non-point sources. The point sources include the municipal sewage treatment plants. There are a total of four plants that discharge into the harbour, the largest of which is the Woodward plant (at the time of this report), which serves much of the City of Hamilton - it is discharged into Red Hill Creek and flows into the harbour. The remaining three plants - Skyway, Dundas and Waterdown, are much smaller in comparison (Rodgers et al, 1988, 125). At the time that the 1988 RAP report was published, the facilities were getting close to the maximum capacity that they could hold. This has become an issue that needs to be addressed in the future, as will be shown later in the paper.

The next major point source of pollution is industrial waste. Both Stelco ${ }^{9}$ and Dofasco, the two largest steel plants in the region, discharge their treated

\footnotetext{
${ }^{8}$ Conventional pollutants include phosphorus, nitrogen, oil, chlorides and coliform bacteria.
} 
wastewater directly into the harbour as well as into the municipal sewage treatment plants (Rodgers et al, 1988, 126). The other smaller companies located around the harbour dispose of their waste in similar manners. Each of the steel plants has control facilities that were found at the time to be efficient at removing the priority pollutants (Rodgers et al, 1988, 127). Some of the major chemicals that these industries release include heavy metals, which have consequently contaminated the sediment near their discharge pipes.

These two companies have made considerable improvements in reducing their levels of pollutants. Since 1966 Stelco has spent approximately $\$ 480$ million for 66 projects concerned with water quality control and this in line with a few other factors had reduced the loadings of various pollutants by 50 to 95 percent (Bixby, 1985, 33). Dofasco also indicated in the 1992 Stage 2 RAP report that it had spent approx $\$ 346$ million on its environmental program that has directly resulted in reducing inputs to the harbour (Hamilton Harbour Remedial Action Plan Stakeholders and Technical Team, 1992, 262). Dofasco has also implemented measures to reduce pollution and has achieved dramatic reductions in its loadings (Bixby, 1985, 33). In a letter of endorsement of the RAP from Dofasco, sent in 1992, it indicated that since 1963 it has spent over $\$ 230$ million on pollution control installations (Hamilton Harbour Remedial Action Plan Stakeholders and Technical Team, 1992, 259). The participation of the companies in making improvements was in part a result of MISA, which required reductions in pollution. Under MISA, the steel and iron manufacturing industries

\footnotetext{
${ }^{9}$ Stelco is officially known as U.S. Steel Canada was purchased by U.S. Steel in August 2007. However, for this paper, it will be referred to as Stelco, as all of the historical documentation refers to the company in this manner. It is still commonly called Stelco in the Hamilton area.
} 
had to identify their point sources, had to monitor their releases and has to submit plans to the MOE on how they were going to reduce/eliminate their toxic effluents.

There are a few other issues in the harbour in regards to pollution. Combined sewer outflows (CSOs) are a third point source of pollution - this is the water runoff from the sewer system in the City of Hamilton. This means that at a time of heavy rains, the sewer system is over capacity and raw sewage flows into the harbour at 26 different locations. The City has since installed overflow tanks, one of which is at the largest CSO, to handle the impact of summer storms on the system (Rodgers et al, 1988, 127). Another contributor to the pollution in the harbour is from the Upper Ottawa Street dump that was closed in 1980. It was blamed at the time for ammonia (among pollutants) leaching into the groundwater and into Grindstone Creek, which empties into the harbour. It was a facility that regularly accepted large quantities of industrial liquid wastes until it was shut down (Bixby, 1985, 32). In addition to the point sources of pollution, non-point sources include atmospheric, agricultural (of which very little was known at the time of this study), road salt, shipping and spills. With all of these contributors to pollution in the harbour, it understandable how the Hamilton Harbour was listed as a Class A AOC. Research beyond the scope of this thesis would have to be conducted to determine how the pollution in the Hamilton Harbour compares to other AOCs in the Great lakes. It is also easy to see why urgent action by the community was needed to improve the health of the harbour.

\subsection{Taking care of Hamilton Harbour: Bay Area Restoration Council}


The Bay Area Restoration Council (BARC) is a non-profit organization that was formed as a result of the Remedial Action Plan for the Hamilton Harbour Area of Concern. The stakeholders who developed and wrote the RAP formed this group. Following the suggestions laid out by the IJC in the GLWQA, BARC is a true stakeholder group, with members from various aspects of the community. The group itself has been together even before BARC was officially formed, as many of the same stakeholders were involved in developing the RAP for the harbour.

\subsection{History: before BARC was formed}

It began in 1986 when work was started on developing the RAP. A group of stakeholders was selected by the government initially or chose to join the group as a result of various recruiting techniques that the federal government used in an attempt to get public participation. This initial group of stakeholders, overseen by the RAP Steering Committee (a federal and provincial body established under the $C O A$ ) was recruited using the various methods as indicated below:

1. The Ontario Ministry of the Environment and Environment Canada supplied an initial list of 20 organizations.

2. All local newspaper items on watershed quality published in the six months prior to mobilization were scanned for names (to be possible participants).

3. All persons involved in a waterfront parks project of the City of Hamilton were identified.

4. The initial list was snowballed. (Sproule-Jones, 95, 1995).

In addition to this formal identification of users, some 2000 members of

the general public became involved though disseminating information about the intent to develop a RAP for the Hamilton Harbour and four public meetings 
(Sproule-Jones, 95, 1995) with stakeholders from 49 organizations and groups contributing to the writing process for the RAP.

The first major task that the stakeholders had was in 1986 when it submitted a report to the federal and provincial governments; this report formed the basis of the RAP (Hamilton Harbour Remedial Action Plan Stakeholders and Technical Team, 1992, 208). In December 1986 the stakeholders formed an education program, whose main goal was to explain the AOC/RAP process and to receive input from the public (Hamilton Harbour Remedial Action Plan Stakeholders and Technical Team, 1992, 208). This program included public advertisements, the publication of newsletters and a meeting with various levels of government concerned (Hamilton Harbour Remedial Action Plan Stakeholders and Technical Team, 1992, 210).

An organization called the Land Use Research Association (LURA), a firm specializing in public consultation, mediation, and educational programs related to environmental issues (Hamilton Harbour Remedial Action Plan Stakeholders and Technical Team, 1992, 207) was hired in order to aid the stakeholders in this process. The act of hiring consultants, external of the counsel provided by the government, was an important decision. It demonstrates that given the tools, stakeholders can work outside of government to devise their own plan. Many meetings and many communication forums with the public were held. It seems that the level of transparency was high in regards to the intent and goals of the RAP, which allows all actors to have full information on the resource and its management. In addition to LURA, a company called JAG Communications was 
hired to conduct a small study of public reaction to the issues facing the Hamilton Harbour. The issue that was ranked the most important was the toxic contamination of the water (Hamilton Harbour Remedial Action Plan Stakeholders and Technical Team, 1992, 280). The study also revealed that many participants were willing to bear some of the costs of remediation but that they were worried that the goals wouldn't be achieved fast enough (Hamilton Harbour Remedial Action Plan Stakeholders and Technical Team, 1992, 284). It is promising that the public supported the RAP from the beginning, indicating that if given the choice, the public is interested in making commitments to their local environment.

The membership of the group was diverse, in order to reflect the interests of the community. Initially 60 individuals were interviewed, 49 of which agreed to join the group and at the time that the report was written, which was 4 years after the consultation began, the number of members of BARC was at 43 with 38 of the original members agreeing to stay on as members despite the fact that the goals for the RAP required a long term commitment (Hamilton Harbour Remedial Action Plan Stakeholders and Technical Team, 1992, 207). This consistency is important as it indicates that the buy-in from the community at that stage was quite strong. In 1992, the membership of the group was as follows:

\footnotetext{
6 provincial and federal agencies

9 municipal organizations

3 special boards and commissions

8 industry and agriculture groups

7 environmental groups

6 recreational groups (mainly boating)
} 
The remaining 10 were general interest, i.e. neighbourhood groups, citizens at large. (Sproule-Jones, 1995, 94)

The diversity of the members has allowed the group to take into consideration issues that might not have been explored had the membership been restricted to only the members of the community that would be directly responsible for taking steps to make improvements in their use of the water (i.e. the stakeholders that had property rights).

\subsection{The formation of BARC}

Once the initial consultation and the writing process of the RAP were complete, the group moved forward to form BARC. BARC would not only carry out the educational mandate (as listed as one of the recommendations), but it also needed to ensure that there was accountability, to ensure that all the stakeholders would fulfill their obligation. According to its website, the main purpose of BARC is to:

- Promote, monitor and assess the implementation of the Hamilton Harbour RAP;

- Promote protection and appreciation of the Hamilton Harbour watershed ecosystem;

- Assess and enhance the public's awareness and understanding of the environmental status of Hamilton Harbour and its watershed;

- Promote and develop public information and education programs;

- Provide advice and information to relevant government bodies in support of environmental protection and restoration plans for the Hamilton Harbour watershed; and

- Coordinate activities with those of other organizations and individuals with complementary objectives. (Bay Area Restoration Council).

In order to accomplish these goals, BARC has established four committees, each of which are responsible for a different area. The four main 
committees are: Public Awareness (charged with communication), Monitoring, Fundraising and the Education committee. While the Board of Directors meet regularly (Interview with BARC member or affiliate, October 2008), the committees generally meet on an ad hoc basis. All of the committees are very important, however the one that is arguable most important to the RAP is the Monitoring Committee. It is mainly responsible for putting together the Toward Safe Harbours report each year, which is arguably one of the more important tools in monitoring the progress of the RAP. Some of the major initiatives of the group include: the Adopt-a-Creek program, the Stream of Dreams, the Classroom Mini Marsh program, Yellow Fish Road programs and a community event series. Each of these programs is tasked with educating the public, both young and old alike, on different aspects of the harbour, such as the wildlife, and the effect that humans have on the water.

BARC was incorporated in a by-law (Hamilton Harbour Remedial Action Plan Stakeholders and Technical Team, 1992, 305). This by-law established that there would be five directors elected by the stakeholders, each with two-year terms, to a maximum of three consecutive terms. This is a good policy as it ensures that different stakeholder groups can be represented on the board. The by-law also states that all decisions are to be made based on a majority of votes, with the stipulation that there must be a quorum in attendance. The group established two classes of members, ordinary voting members, who at the beginning paid membership fees, and association non-voting members. This was one way in which the group was able to raise some funds, however it is 
interesting because it means that those who chose not to pay fees did not have a chance to vote on the important issues. The implication of this is that it was exclusionary. The group later changed this mandate, as will be examined in chapter 5 . One feature that was missing in the by-law was a mechanism for resolving conflict in the group, which may be problematic in collective action initiatives, and will be explored later in this paper.

\subsection{Taking care of Hamilton Harbour: Bay Area Implementation Team}

The stakeholders, after creating the RAP, made a decision to form two stakeholder groups. The first was BARC, which was the public voice for the Hamilton Harbour RAP. The second group, the Bay Area Implementation Team (BAIT), officially formed in 1993 (as per the 1992-1993 BARC annual report), is a much smaller organization, with 18 members (as of January 2009). It was tasked with implementing the plans outlined in the RAP (Hall, O'Connor, and Rainer, 2006). BAIT is separated from BARC because the members of BAIT had ownership of the land or water, have jurisdiction in the area and/or are directly contributing to funding the remediation of various aspects of the RAP (Interview with BARC member or affiliate, October 2008). Another reason for separating the two groups was that the Ontario MOE did not want to delegate budget and operational control to a mixed stakeholder group (personal correspondence, February 2009); it did not want to "lose power and control over the RAP process to local interests" (Sproule-Jones (b), 2002, 851). BAIT is overseen by co-chairs from the federal and provincial governments whereas BARC is seen as the public voice of the RAP, and does not include the government among its members. 
BAIT is made up of senior level managers of their organizations and according to Hall et al, it has four main benefits: collaboration (between groups that don't normally work together), buy-in (because of the high level membership), leadership (established for individual projects) and peer review (at each meeting, which creates a peer pressure) (Hall, O'Connor, and Ranier, 2006, 15). This last point, the peer review, is interesting, as Hall indicates that because members are required to report on their progress at each meeting, they have to be accountable for not only their progress but also any delays in implementation. What isn't clear is whether or not this system encourages collusion between the more powerful stakeholders. There are 18 stakeholders in this group, including industry, provincial and federal governments, the Hamilton Port Authority, McMaster University, the Royal Botanical Gardens, and local conservation authorities. This method of organization of the RAP is quite different from other RAPs. This separation has made the RAP unique, and some would argue, has contributed to the success of the RAP.

The fact that the stakeholders were split up into two groups is interesting, and may have both a positive and negative impact on the remediation plans. While all stakeholders had a say in what the RAP would be at the beginning of the process, the actual logistics of implementing the plan is in the hands of the BAIT. This is good in the sense that because BARC and BAIT are separate, BARC can maintain its position as the public voice in order to ensure that that the BAIT is meeting its responsibilities. However, the one negative point about separating the two groups is that it separates the stakeholders that have power 
from those that don't. Those stakeholders from BARC that are also members of BAIT, in effect, are designated as more powerful, and as a result, potential abuses of power can occur. This happened in the case of Randle's Reef (which will be explained more in depth in the section on conflict resolution mechanisms) when the plan for remediating the contaminated sediment was stalled when it reached the implementation stage because some of the major power brokers, Environment Canada and Stelco, altered the original plan. The plan was revised, but not without conflict. This power imbalance is a concern and is revisited in subsequent chapters in the context of collective action theory.

\subsection{Summary}

The first section of this chapter illustrated how some of the major stakeholders in the harbour have contributed to the levels of pollution that have had detrimental effects on the water. These effects have in turn affected other users of the harbour, as well as the wildlife, as is indicated with the effect that pollution has had on the fisheries. It is because of this integration between those who cause pollution and those who are affected by it, that the RAP, developed by stakeholders, and, BARC and BAIT, formed once the RAP was defined, are important in the remediation of the harbour. These avenues provide the various stakeholders with the opportunity to exchange ideas and to understand the viewpoints of each other, and to work collectively to remediate the Great Lakes, either by educating the public or by determining how to implement the RAP recommendations. 
BARC and BAIT were established under the GLWQA, and as such, are one more layer in the administration of the RAPs. They are arguably the most important aspect of the GLWQA because they are most closely connected to the harbour. The potential for power struggles as a result of separating BARC and BAIT raises additional questions that are explored in chapter 5 . The IJC, the GLQWA, the various levels of government, and BARC/BAIT all work together to achieve the goals of remediating the RAP, with BARC and BAIT ensuring that progress continues on the long road to delisting in 2015. 


\section{Chapter 5 - Designing a collective action group}

Managing natural resources is difficult, especially if it is a resource like water, which is dynamic and as a result, the actions of each user has an affect on the other users. The disposal of waste into the commons is an even larger problem, and perhaps because it is so difficult to define the rights to a resource such as water, it is also difficult to determine who is responsible for cleaning up the resource when it is polluted. How then, in the case of polluted water, should the remediation be handled?

Ostrom's principles will be the main focus of this paper, however, this chapter will also explore the work by other theorists to see how their work compares to Ostrom. Each of Ostrom's principles is applied to the Hamilton Harbour RAP, showing how it does or does not meet the principles. This includes looking at the documentation of the RAP and evidence from interviews in order to identify the challenges the group faces. Much of the literature on the commons or collective action or co-management has to do with the use and appropriation of resources. Little work has been done on the review of collective action steered towards the remediation of resources from the effects of pollution, as is the case with the Hamilton Harbour. This thesis attempts to understand the issue of remediating natural resources, and how to do it within the context of a collective action group that tries to improve the quality of a public good such as water that is used by diverse stakeholders. 


\subsection{Well Defined Boundary for the Resource}

The first design principle Ostrom describes is that the boundaries of the resource in question should be well defined, both in terms of geography as well as in terms of those who have the rights to use it. The better defined a resource and its users are, the easier it is to monitor the resource and to determine who is or is not using the resource in a manner that does not harm the resource or negatively affect other users.

When the Hamilton Harbour was identified as an AOC 1985, it was done so because of the extremely high pollution levels in the harbour water. The AOC was defined as the area contained within the harbour (primarily), as well as the tributaries that feed into the harbour (secondary). Although the resource is water, and that water moves from the harbour to the main body of the lake, the boundary, (i.e. the water contained within the boundary of the harbour) is well defined, and is clear to all users. An ecological approach to remediation means understanding all the factors that contribute to the pollution in this body of water and as a result, the secondary definition of the boundaries, the Hamilton Harbour watershed, has to be included, as it has an effect on the quality of the water as well. This secondary boundary is still fairly clear though more complex to manage. As of the time of this report, the main focus has been on treating the water in the harbour itself, however the RAP is working towards including the watershed in its future plans. The fact that the physical boundaries of the resource have been easy to define has made the remediation process move smoothly, i.e. there is no conflict over the geographic boundaries of the harbour. 
The second way to define the boundaries of a resource is in terms of the rights to the resource itself, and the users that will be involved in the collective action group. The boundaries of the resource and the rights to ownership of the resource are important because it sets the stage for all of the other requirements for a sustainable resource. If the resource and the rights to it can't be defined, how then can the governance structure be established? In the case of the Hamilton Harbour, those who have property rights within the Harbour are clearly defined.

The Hamilton Port Authority (HPA, formerly known as the Hamilton Harbour Commissioners) holds a large share of the property rights in the harbour. The Hamilton Harbour Commissioners was established as an independent agency under the Hamilton Harbour Commission Act of 1912, and in 2001 the federal government acquired ownership of the agency and renamed it the Hamilton Port Authority. The HPA has rights to all waters and inlets of the bay, and all waterfront properties, water lots, docks, shores, and beaches in and along the Hamilton Harbour (Rodgers et al, 1988, 49), although there are private owners around the harbour. In addition the HPA owns the bottom of the harbour as well as 600 acres of shoreline (Interview with BARC member or affiliate, 2008). All dredging activity and harbour construction must receive the approval of the HPA. There is also a by-law that gives priority to commercial shipping over recreational boating, and the HPA charges a fee for traffic destined for private wharfage such as Dofasco and Stelco. The HPA also leases land to many 
recreational boating groups. There are 14 commercial piers in the Hamilton Harbour, 10 of which are owned and leased out by the HPA.

The federal government also has some ownership of the land in the harbour. The Department of National Defence owns a pier, and the Canada Centre for Inland Waters owns two piers as well as the adjacent land. The federal government also has complete control over the navigation and shipping of the water under the Navigable Waters Protection Act and the Canada Shipping Act. A large portion of the harbour coastline is owned by large industry, in particular the steel industry. The local conservation authority, the Hamilton-Wentworth Region Conservation Authority, has complete jurisdiction over Cootes Paradise. This area is located at the far end of the harbour and is not used as a shipping area. As a result the $\mathrm{HHC}$ relinquished its control of this area (Rodgers et al, 1988 52). In addition, the cities of Burlington and Hamilton have ownership of some of the land adjacent to the Harbour, as do private landowners. The municipal governments typically have jurisdiction over the use of all lands and improvements within the city boundaries. Based on the fact that the HPA has jurisdiction over the Harbour, it was ruled that city by-laws affecting the land use within the harbour are only applicable when they do not interfere with the shipping and navigation related purposes (Rodgers et al, 1988, 52). The province of Ontario does not own any property around the harbour. The only power that it has is control over the legislation governing the companies that release effluent into the harbour (Rodgers et al, 1988, 50). While there are multiple property owners in and around the harbour, each property owner's rights are clearly 
defined. The implication of this is that it determines who has the obligation to remediate the harbour, as was laid out in the RAP. This in turn affects the rights of the public who use the harbour as a site for recreation.

The number of levels of ownership has a way of making the negotiations difficult but in the case of the Hamilton Harbour, the boundaries are very well defined. But the focus of the RAP since its inception has been on the harbour itself, not on the watershed. BARC has changed this in the past couple of years and has started to work towards putting more of a focus on the watershed (Interview with BARC member or affiliate, 2008). This will add to the list of key stakeholders above, as more municipalities and agricultural interests will be added to the mix. The complexity of taking a watershed approach arises from the fact that the actions of the property owners within the watershed will have an effect on the water quality of the harbour. It will be difficult to determine who exactly is responsible for which emissions, since the tributaries that feed into the harbour are dynamic. For example, there could be two owners located on one creek, both in the agricultural industry. If pesticides were leaching into the water supply in that creek, it could be difficult to determine who exactly was responsible for the pollution. This means it will be more challenging to fulfill the principle of a well-defined boundary. Despite this possible complication in the future, to date the harbour itself has been clearly defined, and this clear definition has been important to the success that the RAP has made in restoring the harbour thus far. 


\subsection{Proportional Equivalence between Benefits and Costs}

For collective action to be successful there needs to be proportional equivalence between the benefits and costs of using the resource in a sustainable manner. The benefits and costs can be examined financially (direct and indirect) as well as socially. This is an important principle as it can make the difference between getting stakeholders to buy in to the plan or to refuse to participate.

Estimating the benefits and costs, particularly the benefits, in the case of the Hamilton Harbour is difficult, but it has been necessary in order to have all stakeholders buy-in to the process, including the public and the government. Direct financial benefits are extremely difficult to estimate, and have not been calculated for the Hamilton Harbour RAP. The Stage 2 report of 1992 indicates that studies had been conducted on the costs of remediation but not the benefits. However, it is possible to have indirect financial benefits to cleaning up the water. The 2002 Stage 2 update for the Hamilton Harbour RAP indicates that it was expected that the spin-off benefits of the RAP would come in the form of indirect benefits to the economy and an improved community image (Hamilton Harbour Remedial Action Plan Stakeholder Forum, 2003, 181). For example, a cleaner harbour could attract more national and international boating events (in 2007 the Hamilton Harbour Yacht Club hosted the Canadian Yachting Association National Sailing Championships in August, International Sailing Federation). Events such as this increase tourism revenue in the area, and instil a sense of pride in the residents of the city. 
The costs of cleaning up the harbour are much easier to define. As the RAP stipulated, there were various parties responsible for the remediation. Some of the expenditures were spent before the Stage 2 RAP report was finalized (mainly by municipalities), as the 2002 Stage 2 Update report on the status of the RAP indicates (see Table 4). Once Stage 2 of the Hamilton Harbour RAP was finalized, the federal and provincial governments started to contribute funds (see Table 4). This report also estimated the expected costs, both capital and annual, for the remaining years until the targeted AOC delisting date in 2015 (see Table 5). The government (federal, provincial, and municipal) has and needs to spend a large portion of the budget to improve the sewage and wastewater treatment plants that empty into the harbour. They have been also been responsible for funding much of the research that goes into monitoring the harbour.

Table 4 - Past Expenditures for the HH RAP - 2000 and before

\begin{tabular}{|l|l|l|}
\hline In millions, 1990\$ & Pre 1990 & $\mathbf{1 9 9 0 - 2 0 0 0}$ \\
\hline Federal Government & & 30.22 \\
\hline Ontario Government & & 30.14 \\
\hline $\begin{array}{l}\text { Municipal governments, industry, } \\
\text { and other }\end{array}$ & 600 & 145.05 \\
\hline
\end{tabular}

Remedial Action Plan for the Hamilton Harbour: Stage 2 Update 2002 http://www. hamiltonharbour.ca/rap/reports.htm, 183 
Table 5 - Preliminary Cost Expenditures for the HH RAP 2000-2015

\begin{tabular}{|l|l|l|}
\hline RAP Component & Capital Cost & Annual Cost \\
\hline & \multicolumn{2}{|c|}{$\$ 1990$ in millions } \\
\hline Water Quality and Bacterial Contamination & 543 & \\
\hline Urbanization and Land Management & 10.11 & .777 \\
\hline Toxic Substances and Sediment Remediation & 81.02 & .048 \\
\hline Fish and Wildlife & 8.51 & \\
\hline Public Access and Aesthetics & 19.7 & \\
\hline Education and Public Information & .096 & .933 \\
\hline Research and Monitoring & & .74 \\
\hline Totals & 662.436 & $\mathbf{2 . 4 9 8}$ \\
\hline
\end{tabular}

Remedial Action Plan for the Hamilton Harbour: Stage 2 Update 2002 http://www.hamiltonharbour.ca/rap/reports.htm, 184

These benefits and costs can be measured in financial terms, but there are other benefits and costs to consider, as Kopelman et al indicate. Studies have been conducted that indicate that in common pool resource situations, the combination of social familiarity and social rewards such as the expression of appreciation after the fact, encourages cooperation amongst participants (Kopelman, Weber, and Messick, 2002). Baland and Platteau agree, indicating that social reputation plays an important role in whether or not a user will work towards a collective action group - users want the benefit of being seen as socially responsible (Baland and Platteau, 2000, 231). This is possible, providing that the group has the capability (socially and financially) to solve the resource problem at hand (Singleton, 2000, 2). In the case of pollution, as can be seen with the case of the Hamilton Harbour, it is often difficult to measure, in financial terms, the benefits of restoring the natural resource, and thus emphasis needs to be put on the non- 
financial benefits of cleaning up the pollution, and the costs of continuing to pollute.

While the indirect financial benefits of a healthy harbour are important, the non-financial benefits are arguably more important. A restored harbour is not only beneficial for the wildlife, but also the community, as it can become a gathering place. The detrimental effects of having a polluted harbour include a lack of healthy ecosystem, as well decreased enjoyment of the harbour polluted water smells bad, it looks bad, and it often contains dead and sick fish around the harbour. Boaters, when exposed to polluted water can develop skin rashes. The level of pollution in the harbour should not be a health risk to the wildlife or the residents in the area. Reversing this trend of pollution would help improve all of the above situations. Another intrinsic benefit is that of an improved community image. If the city has a reputation, such as Hamilton, as a city that is polluted, it can be hard to attract new residents, potentially making it difficult for business to attract new talented labour to work in the city, simply because it does not seem like a desirable place to live. In addition to the benefits of having a clean harbour, the active stakeholders can increase their social capital by actively engaging in remediating the resource. Outlining the benefits of remediation is one area in which the Hamilton Harbour RAP needs to improve. In order to get more buy-in, especially from business, the benefits need to be estimated. While this is a complicated set of data to estimate, it could provide the group with more substance to the arguments of having a cleaner harbour. 
One of the key points that Ostrom outlines is that the distributions of benefits needed to be consistent with the distribution of the costs in order to convince participants to buy-in to the plan (Ostrom, 2005, 263). This is not the case for the Hamilton Harbour, mainly because most of the benefits are either indirect (financially) or they are intrinsic. This makes remediation difficult because the benefits of the harbour cannot be shown until the harbour is clean. In the case of the Hamilton Harbour, all of those responsible for the implementation have made significant contributions, but it remains a priority to ensure that they continue to support the RAP financially. Unlike resources that are harvestable, which are mainly resources that Ostrom refers to in her research, the benefits of having a clean environment are more difficult to measure. In the case of the Hamilton Harbour the active stakeholders need to recognize that by reducing their pollution, they can have a positive impact on the harbour. The Hamilton Harbour would benefit from a formal cost-benefit analysis, as the indirect benefits could be substantial, and estimating them could create more public support and consequently more political will to continue funding the remediation.

\subsection{The Presence of a Collective Choice Arrangement}

A third requirement for a sustainable resource management system is that there is a collective choice arrangement. This collective choice arrangement should be made available to as many members of the public as possible. The public not only has the greatest stake in what happens in the community but is also a source of knowledge that can be exploited to the advantage of the natural 
resource. As chapter four outlined, the initial group of stakeholders that developed the RAP not only includes those with a direct stake in the harbour, but also the public at large; this means, that because of the property rights for the harbour, as explained in section 5.31 above, some federal agencies are considered as stakeholders. Most collective action groups, including the Hamilton Harbour, are made of diverse populations and interests and this can impact how effective the group can be (Ostrom, 2005, 252). Stakeholders in the Hamilton Harbour RAP represent industry, government agencies, educational institutions, conservation authorities, and environmental, community and recreational groups, as well as citizens at large. Disagreement can occur, as is explored further on in this chapter. It is easier of course, to come to an agreement if interests are similar. If the views of all those represented are taken into consideration in the development of the agreement, the group can still succeed. The best approach is to make the process open to everyone with a stake in the resource - including passive stakeholders - in order to get as much public buy-in as possible.

While the techniques to recruit the stakeholders were broad, it had to be in order to build legitimacy for the project. The interests of the group were diverse, representing small and large stakeholders, as well as those who have a financial stake in the harbour and those who are interested in the environmental or recreational aspects of restoring the harbour. What isn't clear about the participants in the group is what socio-economic background they come from, and whether diverse socio-economic backgrounds were represented in the 
group. The Hamilton Harbour RAP was established under the principle that as many people, from as many interests as possible should be included in the RAP. This in part has made the RAP successful because the broad reach of the group, and the attempts to reach the public at large, has ensured that many views about the plan for the harbour were shared with the RAP steering committee, and ultimately included in the RAP itself.

A collective action group must also communicate its goals effectively to the broader public in order to be seen as legitimate. Part of communicating this information about the group is that the benefits of remediation need to be shared with the public; rational choice analysis in the case of a stakeholder group implies that none of the parties would participate unless they felt that they would directly benefit in the bargaining position (Adger, Brown and Tompkins, 2005). Once the RAP was developed, BARC took on the role of informing the public about the RAP, its progress, and the harbour itself through its newsletters, strongly establishing the legitimacy of the group with the public.

The newsletter that BARC produces has evolved from a publication that revealed the major difficulties that the group is facing, into a conduit to educate the public about the harbour, encouraging the public to get involved in the events happening in and around the harbour and making them aware that the harbour is a great place to spend time. This is a good tool for challenging the stereotypical image that residents might have about the harbour (arguably one of the biggest challenges BARC has is to convince the public that the harbour conditions have improved because it has been polluted for so long and public access was 
limited). This change in the newsletter is a good one - one of the most important ways to ensure that progress is continually made in the harbour is to create an environment in which the residents feel that the harbour is worth protecting. This creates political will, a political capital that the organization needs in order to continue to build political support, and ultimately financial support, for the remediation of the harbour. The change in the tone of the newsletters reinforces the is one way in which the Hamilton Harbour RAP is fulfilling Ostrom's principle of a collective choice agreement; it is informing the public in a clear manner and ensuring that the issues affecting the Hamilton Harbour are in the forefront of the public eye.

The effect that the size of the group has its ability to engage in collective action may have an effect on how the group itself works. Much of the available research has concluded that smaller groups work more efficiently than larger groups at preserving the resource (Ostrom, 2005, 251, Baland and Platteau, $2000,231)$. Smaller groups have a great ability to communicate, which Ostrom's laboratory research has indicated leads to more effective resource management; however, it is not clear how many stakeholders make up a small group. She indicated that "face to face communication proved to lead to decision making that was beneficial to the resource" (Ostrom ,2005, 86). Ostrom indicates that researchers have taken her work and expanded on it to discover that small groups and large groups are more effective in managing a resource than the medium sized groups, although she points out that the larger a group gets, the more variables are at play, making it hard to determine if size hinders or aids the 
preservation of the resource (Ostrom, 2005, 252). Not all research on group size indicates that small groups are better. Further research that indicates that smaller groups could encourage free-riding as a result in the "increased assessments of the efficacy of others' cooperative behaviours" (Kopleman, Weber and Messick, 2002, 133). It is not clear if Ostrom would consider the Hamilton Harbour RAP as a large, medium or small collective action group, because she does not specify the number of participants that determine into which category a group may fall. This discussion has illustrated that size is not a determining factor in the success of, but it can be important, and often a smaller group does lead to success.

Rules have to be established for a collective action group. The individuals affected by a resource regime need to be authorized to participate in making and modifying their rules (Ostrom, 2005, 263). This allows the locals to be empowered, and as a result they will follow the rules more frequently in this situation, than if the rules were imposed on them from the outside (Ostrom, 2005, 264). Some theorists think that the property rights should be defined from within the group (Ostrom, 2005, 264). Sneddon, basing his research on a case of water pollution in Thailand, indicated that the roles for each participant and the role of the state must be clearly defined, in order to encourage better participation from the members of the group. Often, if the decisions are made externally from the community, the community can be resentful, and be more hesitant to participate. The more the group determines its own direction, whether in terms of the rules that it follows, or the property rights that each user has access to, the greater the 
participation from the group, because they have made a conscious choice to manage the resource in the way they see fit.

The organization of the RAP in Hamilton was very different from other RAPs in Ontario. The stakeholders were able to define the terms of their existence and the "rules" that they would follow in order to come to their decisions. The key to this group, which distinguished it from other RAPs in Ontario was that:

Some stakeholders' interests [were] nested within wider constitutional governance systems (such as commercial shipping), placing constraints on the ability of the RAP Steering Committee to raise entry rules and lower aggregation rules. Such was not the case with twelve other areas of concern on the Canadian side of the Great Lakes:

Stakeholder interests were to be included only through public advisory committees on the plans developed by governmental agencies (Sproule-Jones, 95, 1995).

This means that because of the different levels of jurisdictions that were within the Hamilton Harbour when the RAP was first developed, specifically the Hamilton Harbour Commissioners (now the Hamilton Port Authority), the constitutional rights of that group overruled the rights of the RAP steering committee, which ultimately gave the Hamilton Harbour RAP stakeholders more "power" to determine their own rules. This allowed the Hamilton Harbour RAP to become a RAP truly determined by stakeholders, and as a result it is a true collective action group.

The method in which the rights for the stakeholders are distributed is important in the development of the group. The rights of one user must not be privileged over the rights of another user in collective choice institutions (Sneddon, 2002, 734). Agrawal and Gibson indicate that collective choice 
institutions allow for the promotion of stability before the work is started, and consistency in expectations, once the work has begun (Agrawal and Gibson, 1999, 637). They also indicate that institutions can help diminish some of the power imbalances that normally exist in conserving resources. They indicate that this is in part accomplished by the fact that the institutions help define the interactions among users and around the resource itself (Agrawal and Gibson, $1999,638)$. It is not clear though how this reduces power imbalances amongst users, other than the fact that if the institutions have rules and purposes that are well communicated, it becomes more difficult for the more powerful to change the rules without everyone else knowing. Agrawal and Gibson do indicate that institutions do not set the terms of interactions amongst the parties, rather they mimic what already existed in the community before the institution was in place; they are, in a sense, provisional agreements on how to accomplish the goals of the collective group (Agrawal and Gibson, 1999, 638). If there is a power imbalance, it is possible that the rules were defined to meet the interests of the more powerful, resulting in a similar imbalance to that that existed before the institution was in place. However, if all members do not agree to the rules, then the group itself would fail.

In the case of the Hamilton Harbour, as was discussed in chapter four, there is a possible imbalance of the rights amongst the stakeholders. This imbalance exists in the separation between BARC and BAIT, and as a result potentially gives the members of BAIT more power than other members in the RAP. The RAP Stage 1 and Stage 2 reports were developed by all of the 
stakeholders. However, in the Stage 2 report, BARC and BAIT were separated, which essentially gave those who have property rights and/or who are contributing financially to the remediation of the harbour, more rights. On the one hand it is important, as in the case of the Hamilton Harbour, that the shareholders who have greater property rights and financial abilities to contribute to remediation, have more power to determine how they are going to enact the plan, because it can give these stakeholders greater incentive to continue to be active members of the RAP. Because these are the larger players in the harbour, their buy-in is essential to ensure the success of the RAP. This is important since, as discussed earlier, the financial benefits of remediation are not direct, while the costs, especially to these stakeholders, are quite high. On the other hand, this arrangement encourages a situation, such as the case of Randle's Reef, where a few stakeholders could decide to alter a plan that had already been established by the majority of all stakeholders in the harbour, in order to suit their specific needs.

Randle's Reef is natural rocky area in the Harbour, some 5 to 8 metres below the surface, and adjacent to the loading docks of Stelco (Sproule Jones (a), 2008, 193). As Sproule-Jones indicates, it is second only to the Sydney Tar Ponds in Nova Scotia, with PAH levels that exceed 800 million parts per million. This issue has been debated since the initial RAP was developed. At the beginning of the RAP process it was agreed at a meeting of BARC stakeholders and citizens that the sediment would be removed, by Environment Canada, the MOE, and Stelco. This agreement soon fell apart once the logistics of who would 
be financially responsible to pay for the remediation started to unfold.

Environment Canada proposed that the costs be split evenly between itself, MOE and Stelco. The MOE was initially on board but Stelco, which denied that it was responsible for the sediment, did not agree. Sproule-Jones indicates that Environment Canada was set on maintaining a good relationship with industry and thus did not push the issue, which eventually, after much political wrangling and positioning on the behalf of Environment Canada and Stelco, lead to the current proposed solution of "confine, fill and cap"10 (Sproule-Jones (a), 2008, 196). Recently, a public meeting was held by the RAP office and Environment Canada in order to inform the public of its latest plan (Bay Area Restoration Council). One of the biggest criticisms that Sproule-Jones makes about this issue is that instead of being a decision made by all stakeholders (active and passive), it was instead the key players that largely made the decision environmentalists were left out and largely unheard. He indicated that one of the largest criticisms of this plan by environmentalists is that by capping the sediment it is leaving the problem for future generations, rather than taking the opportunity at this juncture to actually solve the problem (Sproule-Jones (a), 2008, 196). This imbalance of power enabled the stakeholders with more power to alter the original plan, delaying action on an important issue.

Ostrom has also indicated there are exogenous changes in the resource and/or the social/political/economic situations that have an effect on a collective

\footnotetext{
${ }^{10}$ Confine, fill and cap means confining the sediment at its current location, filling it in with contaminated sediment from other areas in the harbour, and then capping it within a cement structure.
} 
action group. These are uncontrollable and can cause havoc on sustainability of a resource. Some examples of changes within the resource include a time when certain types of birds were scaring off other wildlife that normally bred in the same area (in the fall 1993 newsletter). Another example was with carp that were in an area that had already been netted off to protect it from the carp (this was attributed to a lack of knowledge as well) (in the fall 1993 newsletter). One year, heavy rainstorms allowed the carp to enter a netted area (in the fall 1996 newsletter). Politically and economically, during the time that the Hamilton Harbour RAP has been in existence, there have been two recessions (once of which is in progress at the time that this paper was written), and multiple changes in the provincial, federal, and municipal governments. In March 2009, U.S. Steel (Stelco) closed its factory until further notice, a result of the recession; this will not only have an effect on the ability of this factory to uphold its commitment to the RAP, but also, because these manufacturing jobs support many other jobs within the community, it may be more difficult for BARC to engage the public in its fundraising activities. On the other hand, while the factory is closed, pollution will be eliminated from that source. These are difficult problems for the group to anticipate, and often cannot be solved until the problem itself arises.

The Hamilton Harbour RAP has met the principle of forming a collective action arrangement, as per Ostrom's principles, and has been quite successful at getting involvement from a large variety of stakeholders. It was particularly successful at reaching a broad range of interests in the initial stages of developing the RAP, and still continues this outreach with annual community 
workshops. One problem is that there is an issue of power imbalance with the establishment of BARC and BAIT, however information in chapter three indicates this was necessary in order to ensure the involvement of the provincial government. This imbalance has caused problems, as the case of Randle's Reef illustrates.

\subsection{Monitoring}

Another important component for sustainable common property resource management is the idea of monitoring. This is the idea that there are people who monitor not only the conditions of the resource, but also the users of the resource.

In the Stage 2 RAP Report for the Hamilton Harbour there is an outline of who is responsible for data collection and what data will be collected in order to monitor the progress of the remediation. The RAP team takes monitoring very seriously, and has worked hard in order to ensure that accurate and useful data are obtained. Certain parties were given monitoring responsibilities. Conservation authorities and the Ontario MOE were implicated as parties that already monitor the streams and watershed. The 1992 Stage 2 RAP report suggested that the parties should increase the monitoring frequency as well as change the location in order to better identify problem areas. The Ontario MOE is responsible for measuring the quality of the water in the harbour and it was recommended that they add more monitoring sites, as well as change the location of a few, in order to get better data. The Ontario Ministry of Natural Resources was listed as the group responsible for measuring fish tissue samples but the federal Department 
of Fisheries and Oceans, which was already monitoring fish populations at the time when the report was written, will continue to monitor the effects of remediation on the fish. The Hamilton Harbour is extremely well placed to develop a strong monitoring regime for the resource. In addition to the stakeholders listed above who are responsible for monitoring, McMaster University, has been actively involved in monitoring the resource, as well as the Canadian Centre for Inland Waters (CCIW), which houses the National Water Research Institute. Stelco and Dofasco have each contributed to the data set, as they are required to monitor their data in order to report to the National Pollutant Release Inventory (NPRI). The number of organizations implicated in monitoring the data is promising, although it could be improved. The data collection still has gaps, but the situation has much improved and has allowed the BARC monitoring committee to put together a report card on the status of the RAP (2002 and 2007). Yet despite this, as will be seen with the analysis of the newsletters annual reports that BARC produces, there is still concern amongst the stakeholders that there is not enough data or that funding will be cut for the data monitoring programs in place. They have emphasized in their TSH reports that in order for the Hamilton Harbour to meet its remediation goals consistent funding for monitoring is required.

One of the benefits of monitoring the CPR and its users is that it increases accountability. It can increase the communication of expenditures (costs and time) and resource conditions to the funding partners as well as the users, and it can increase interest in the remediation efforts because the results of the work 
may be more apparent (Hall, O'Connor and Ranier, 2006, 12). It is important that monitoring is consistent and that the results are useful to the users. Some have indicated that some challenges with monitoring is that it is often conducted by those with specialized knowledge, and that if those people retire or move on to other phases of their career, it could leave a gap in information, to the detriment of the resource (Hall O'Connor and Ranier, 2006, 14). Hall et al recommend that it would be useful to have a mentorship program in order to ensure the continuation of monitoring once key people have left the project. (Hall, O'Connor, and Ranier, 2006, 14). Another issue is that funding needs to be consistent for monitoring, again, because discontinuity in the data makes it difficult to manage the resource. Monitoring the resource is an important component of the management of CPRs - if the resource is not monitored, it is nearly impossible to tell who is living up to the agreement, and whether or not the resource and its users are benefiting from it.

BARC itself has a Monitoring Committee, which every year assembles the Toward Safe Harbour (TSH) Reports that monitor the progress of the RAP. This is one of the main tools used in order to ensure that all members are accountable for their actions. Since the first TSH report in 1994, the style of the report has changed with the most frequency, compared to the newsletters and annual reports that BARC produces. The TSH started off as a report that listed each of the 50 RAP recommendations and evaluated the progress that was made for each of them. It then evolved to a report that would focus a small section on one issue, i.e. non-point source pollution, sewage treatment plants, etc. and then 
discuss the contributions of the different types of stakeholders (i.e. government, business, etc) with an update on the 50 RAP recommendations included in the appendices. In the past 6 years, the report has included a report card style format every 5 years, starting in 2002, with the remaining four TSH reports focusing on a specific topic. This change in reporting style seems to have been done to ensure the RAP is monitored, so that the public and the stakeholders have evidence of how well the RAP is or is not progressing. If work has not been progressing in a certain area, it is clear who is responsible for that part of the remediation process, and that they have not met their expected targets.

A review of the reports indicates that insufficient monitoring data has been a consistent problem. In the 1997 report, the authors indicated that it seemed that the governments were not monitoring the harbour above and beyond the requirements of MISA, which unfortunately meant that not enough data was being collected. In recent years, the monitoring committee that assembles the TSH has indicated that one of the larger concerns is that monitoring programs need to be long-term programs to ensure consistency of data (TSH 2008). They also indicated they are concerned that because so much knowledge is held by key experts that once these experts retire, there will be a loss of corporate memory (TSH 2008). The stakeholders have to be vigilant in order to ensure that monitoring is continuous, and they need to address challenges that might interfere with the ability of the RAP to be monitored.

Accountability in the Hamilton Harbour also comes from ensuring that companies meet the pollution regulations, as set out by the province (described 
in Chapter 2). This form of monitoring is not in the hands of the stakeholders rather it is a function of the governments, primarily the provincial government. When MISA was in effect, it required that Stelco and Dofasco, as well as the cities of Hamilton and Burlington, report their emissions and meet certain thresholds as outline in the act. It is important to note that the industries themselves are responsible for implementing the monitoring system (Ontario Ministry of the Environment (c)). In addition, there is also the Certificate of Approval process that the province of Ontario has developed. These programs have helped to reduce the amount of effluent being released into the harbour, and have made a contribution to the overall health of the harbour.

There is a third informal type of monitoring that is carried out by BARC. BARC brings public attention to any sort of environmental issue concerning the harbour through workshops, newsletters, a monitoring catalogue and the Toward Safe harbours report (Hall, O'Connor, and Ranier, 2006, 7). BARC does so in a couple of ways. The first is by bringing the positive news to the public concerning the harbour. BARC produces newsletters 4 times a year, and the style of this newsletter has changed since the first issue in 1994. At the beginning the content in the newsletter was quite word-heavy, and informative. The more recent issues include much less content, making the report more accessible to the general public. Key updates are provided and every once in a while an article will be published which outlines details on a key issue, which is meant to inform the public. It indicates that the group learned from each year that they published, which styles were and were not meeting their needs as well as the 
needs of the public. They have now become much better conduits for sharing information and getting public buy-in for the issues of the harbour.

The interviews revealed that many within the organization felt that the Towards Safe Harbours Report was one of the most important tools that BARC uses in order to build public awareness and stakeholder accountability. One respondent indicated that the report was a great way to build political support, because politicians, in particular city councillors, could see where their government was falling short, and could use it as a way to influence budget and policy decisions (Interview with BARC member or affiliate, 2008). One respondent indicated that BARC's role as not only a public voice but also a collaborator was extremely important (Interview with BARC member or affiliate, 2008). This meets the monitoring principle as per Ostrom's theories, and allows the public, as well as the stakeholders, to see how far restoration of the harbour has come, and how much work remains to be done.

BARC also draws attention to issues that negatively affect the harbour. In 2000, it was discovered that the City of Hamilton has been knowingly releasing toxics, such as PCBs into the Hamilton Harbour watershed via its Rennie Street dump. BARC was critical of the City, as one of the major stakeholders in the RAP; however, they also worked with the City in order to ensure that it would not allow something like this to happen in the future. By keeping issues about the harbour in the forefront of the public mind, it is possible for BARC to exert a kind of social monitoring; stakeholders are essentially given bad publicity if they do not adhere to the rules agreed upon for the resource. 
Monitoring has been an important part of the Hamilton Harbour RAP. This provides the public with information on the water quality in the harbour, and enables the development of a record of progress for the harbour. Without this data, it would be difficult to hold users accountable for their actions. The RAP does meet the requirements of Ostrom's principle for monitoring the resource.

\subsection{Graduated Sanctions}

Before delving into the concept of graduated sanctions, the rules needed for a CPR and for the stakeholder group need to be discussed. Rules are defined as the tools that are used to determine who can use the resource and how much that individual can use, as well as the actions that are allowed and not allowed, the information that must be provided, and the rewards for following the above requirements (Ostrom, 1990, 51). Ostrom identifies 3 types of rules:

Operational rules - affect day to day decisions made by resource appropriators concerning when, where and how to withdraw resource units Collective choice - rules used by appropriators, officials, or external authorities in making policies about how a CPR should be managed. Constitutional choice - affect operational activities and determine who is eligible and the specific rules to be used in crafting the set of collective choice rules that in turn affect the set of operational rules (Ostrom, 1990, 52).

All these types of rules are important in establishing how not only the resource will be monitored, but also how the sanctions will be applied to those who are not heeding the agreement. Sproule-Jones indicates that rules do not fully determine outcomes or decisions. The rules are dynamic, as stakeholders revise the rules based on learning what has or has not worked (Sproule-Jones (b), 2002, 842). The constitutional rules are especially important as they 
'articulate the stakeholders interests' and how the stakeholders engage with each other (Sproule-Jones (b), 2002, 843). This is key to forming a cohesive group, as once the rules are known, everyone knows where they stand, and what they are required to do (Kopelman, Weber and Messick, 2002, 134). Of course, having each member know what is going on is key to people following the rules. Studies have shown that groups that communicate with each other are more likely to cooperate. Research has also shown that participants often have made an internal decision to follow through on meeting the commitments of the agreement, regardless of whether others keep theirs (Kopelman, Weber and Messick, 2002, 135). In the Hamilton Harbour RAP the collective choice rules are those that were established by the initial group of stakeholders who not only established the RAP but also laid out the rules for BARC and BAIT. The constitutional choice rules for the harbour are rules that have been determined by the various levels of governments such as the regulations that govern pollution (CEPA, MISA, etc.) and water rights in the harbour. The operational rules seem to apply most to the stakeholders that are members of BAIT, as they determine how they are going to implement the RAP recommendations for which they are responsible.

Graduated sanctions mean that the first time a resource user misuses the resource, there is a punishment, but it is low in its severity and acts more as a warning than as a real punishment. They are necessary in order to ensure that all stakeholders are aware that there are penalties when they break their rules 
that they themselves have established. This increases the legitimacy to the group.

This is one area in which the RAP and BARC do not have control, at least in the form of penalties and fines. This is the responsibility of the provincial government. If a company discharges waste into the water above the legal limits or if there is a spill (be it accidental or on purpose), it is the responsibility of the Ontario MOE to enforce the rules it has laid out under its EPA, MISA, and the certificate of approval process. This is one of the areas in which the Hamilton Harbour RAP falls short. One could argue that in order for this group to function more effectively, it needs to have more legal credibility. Because the group has no legal standing, it is really only a group that monitors the resource and acts as its public voice, but it is not a true management regime in the sense that it cannot set and enforce the rules of engagement. It is highly possible, as was the case with Randle's Reef, for an organization to shirk its responsibility, and as a result stall the process of remediation (Sproule-Jones (a), 2008, 196).

Because BARC acts as the public voice for the Hamilton Harbour, it is possible that one of the "sanctions" could be that if stakeholders are not pulling their weight, then the public is made aware of such an indiscretion. An example of this can be seen with the case of the Rennie Street Landfill that the City of Hamilton owned, as examined earlier in this chapter. The City of Hamilton was not meeting its obligations to the RAP, as revealed when it was discovered that the Rennie Street dump had been releasing pollutants into the harbour with their knowledge. In this case, the newsletter asked the questions "Is the RAP 
environment too conciliatory to ensure that our toxic woes will be appropriately resolved? What do we do when it seems that some stakeholders are taking advantage of the spirit of the RAP?" (in the fall 2000 newsletter). This is a large issue as it pertains to how BARC and the RAP itself functions. How does an organization create the balance between a group that creates goals and achieves them by working together vs. holding each individual organization accountable for its actions? Because BARC acts as the public voice, more people are aware when stakeholders do not meet their obligations. This creates a political will that encourages politicians, from local to federal, to make decisions that are beneficial to the harbour. But if the stakeholders are not reprimanded for their inaction, this political will is lost.

Another example of sanctions or lack of sanctions can be seen with the TSH reports. The tone and style of language in the TSH reports has changed since 1994, showing how sanctions have changed as well. The first few TSH reports were very proactive and had an activist voice (for lack of a better word). The reports were much more critical of stakeholders that were not meeting their obligations. The language included terms such as "the need for action is clear"(TSH 1995) and "others feigned great progress while standing still"(TSH 1995), "truly impressive" (TSH 1994) and "real travesty". This is important to note as it indicates that when the group was first established, it attempted to impose social sanctions on the active stakeholders by clearly indicated who was or was not meeting their obligations. After 1996, the language became much more formal, and much less leading in nature. Like the first few reports, the 
stakeholders who contributed to the report were named, and those who didn't were also named, thus truly acting as a monitoring committee and holding stakeholder accountable for their actions or inaction. From 1999 onwards, the TSH reports stopped listing stakeholders, and the tone was much more formal. The last few years especially have shown a preference towards very professional, almost academic overviews of the issue that the report focuses on. This movement towards more professional reports is positive, in the sense that the group maintains its ability to walk the line between being a public voice for the harbour and an organization that is working towards developing an equitable partnership between all of its stakeholders. The fact that the tone changed has meant that the group no longer publicly applies social sanctions, meaning that Ostrom's graduated sanctions principle is not fulfilled. This is a challenge in that it is easier for stakeholders to shirk their responsibilities without being publicly reprimanded.

Based on the TSH reports, it was evident that at the beginning of the RAP process, some stakeholders were not contributing as much to their obligations of cleaning up the harbour. The most obvious 'offenders' were the cities of Hamilton and Burlington, and their sewage treatment plants. The reports indicated that there was little or no progress made on this front near the beginning, however, these groups did turn around and were later listed as active contributors who were making great headway into improving their facilities. This may be in part due to the more forceful language that was used in earlier TSH report, as explained earlier in this chapter. This is further evidence of why it is 
important to have sanctions of some sort, as Ostrom Indicates, to ensure and encourage stakeholders to live up to their commitments.

The ability to develop graduated sanctions is dependent on the fact that the resource is not just managed at a specific point time rather there are cycles of management, that take place over time. A study on the power relations between players indicates that the possible offenders often try to form coalitions among a smaller group of participants in order to protect their own interests, this is especially true when the discount rate (the impatience to wait for benefits) is high. (Kopelman, Weber and Messick, 2002, 129). It is inevitable that when users, especially those who are more powerful, want to exert their own influence over the results, and insist that in doing so, they are not breaking the rules. This is particularly evident in the case of Randle's Reef, as is explored in the previous section, when a small group of stakeholders changed established sediment remediation plans, once they had already been approved by all stakeholders, in order to better suit their needs. Again, the establishment of clear rules and the ability to maintain those rules is one way in trying to avoid this problem.

This is a principle that does not really apply to the Hamilton Harbour RAP. The group does not have power to enforce sanctions, other than by giving negative publicity to the stakeholders that violate the RAP. BARC, at least not in recent years, does not often give bad press to a member. This is in part because if BARC does so, it risks alienating that stakeholder from the process. If the stakeholder feels threatened, it is possible that it could disengage from the RAP process, which would be contrary to the stakeholder approach. This would have 
large implications as this means that the stakeholder would not be implementing the recommendations in the RAP for which it is responsible, a responsibility that was determined by the rights that the stakeholder has within the harbour. This is one principle in which pollution is very different from a collective action group that oversees the consumption of a CPR. It is delicate to punish a stakeholder from within a collective action group in the case of restoring a polluted CPR because, as discussed earlier, the benefits are not as clear, and to punish a stakeholder internally would risk losing the engagement of this stakeholder. In CPRs that are consumer based, it is easier for collective action groups to impose sanctions from within because the offender risks losing a source of income. In the case of the Hamilton Harbour, the stakeholder group could risk losing a key contributor to the remediation of the harbour.

\subsection{Conflict Resolution Mechanisms}

Conflict resolution mechanisms need to be in place in order to ensure that when there is conflict among participants, that there is an agreed upon method in order to solve the conflict and maintain legitimacy of the group. These mechanisms need to be accessible to all members and there should be a higher level at which conflict can be resolved in order to avoid the elite controlling the resource and the processes in place to govern that resource.

Within BARC itself, the formal conflict resolution mechanism is that all issues are discussed and debated. Former members indicated that if the group discusses a certain issue, a decision is made based on debate and majority rules (Interview with BARC member or affiliate, 2008). They also indicated that debate 
is an important part of the process, and that sometimes the debate can last over multiple meetings. While the process can sometimes take a while, it is important to engage in this process because involving the stakeholders at the initial stages will ensure that stakeholders are less resistant to changes in the back end because they have approved of all decisions (Interview with BARC member or affiliate, 2008). If a member is coerced into an idea that they do not like, then they may not agree to do their part in the future to implement the agreement. While this is great at one level, because it means that it is a true stakeholder approach, this does fail in the sense that some members have indicated that some stakeholder organizations or members (mainly passive stakeholders) have withdrawn from BARC because of disagreements over certain issues (Interview with BARC member or affiliate, 2008). Losing members because of disagreement over how to fulfill the mandate of the group is also contradictory to the stakeholder approach.

Baland and Platteau suggest that it would be useful to have conflict resolution mechanisms external to the group, i.e. run by the state. They indicate that this is particularly useful when dealing with the effects of externalities, such as pollution (Baland and Platteau, 2000, 348). Whether the mechanism is internal or external to the group, it needs to be applied in a consistent manner, so as to avoid the elite in the group overriding the decisions of the less powerful. These external conflict resolution mechanisms in the case of Hamilton Harbour could be related to pollution regulations that govern the harbour. The state has 
the role of ensuring that the regulations are not violated and that pollution is reduced.

One of the major issues that has caused conflict within the RAP is the case of the sediment at Randle's Reef. As discussed earlier, two stakeholders changed an implementation plan that had been approved by all stakeholders, both passive and active. This is a good example of how a stakeholder approach can be made difficult when some of the players hold a larger share of the power, overruling some of the smaller players. Sproule-Jones argues that consensual arrangements can be effective when developing the goals but it can fall apart at the implementation level because of incentives for opportunism by the more powerful actors or stakeholders, as in the case of Randle's Reef (Sproule-Jones (b), 2002, 856). Heinmiller et al concluded that although the case of the Hamilton Harbour is promising in that it is a stakeholder democracy designed to give all participants an equal voice, it was clear that Environment Canada still had the tendency towards "state managerialism" that has always had a strong hold in politics in Canada (Heinmeiller et al, 2008, conclusion chapter). If the Hamilton Harbour RAP had a formal conflict resolution mechanism, specifically within BAIT, it could avoid losing stakeholders who disagree with decisions that were made.

\subsection{Minimal Recognition of Rights}

An additional characteristic that Ostrom indicates might not be in all collective action groups, but which is present in the case of the Hamilton Harbour, is the minimal recognition of rights. This means that the right of the 
group to organize is recognized by a national and/or local government. This adds legitimacy to the group, which in turn encourages members to take the group seriously and thus adhere to the agreements that the group has in place.

In the case of BARC, the group is recognized by all levels of government as well as by the IJC. For example the Ontario government set up the Ontario Public Advisory Council to adhere to the suggestions of the GLWQA that the AOCs each have a stakeholder group and active participation from the public in the development and monitoring of the RAP. On the other hand, in 1997 the province of Ontario cut the funding to the RAP. Even though members of the RAP knew that these cuts would be coming eventually, they were not made aware when those cuts would be happening, until the funding was abruptly cut, making it difficult for the group to plan for this shortfall in revenue. This revenue issue is made apparent in a review of the finances of BARC. The government of Ontario did not provide an equal share of funds as Environment Canada, as had originally been agreed upon and of course, cut off their funding completely for BARC, although based on the financial reports, starting in the fiscal year 19961997, and not resuming again until the fiscal year 2003-2004.

This inconsistent and sometimes non-existent funding from the provincial government is a great concern, given that environmental issues are a provincial responsibility. One reason why this might not be a priority for the Ontario government is that the agreement for the RAPs was made between Canada and the US, not Ontario and the US. One would have thought that the CanadaOntario Agreement would have remedied this situation, however, it is clear that 
for a while, the government of Ontario put environmental issues on the back burner. A TSH report itself stated that it was worried that the environment was no longer a top priority in the government (TSH, 1996). This implies that although the Hamilton Harbour RAP has been recognized formally in its right to establish by the federal and provincial governments, that the governments do not always recognize the group in financial (as in providing funding) terms.

Recognition of the group comes not only in the form of funding (mostly from the federal government) but also in the eyes of the politicians. One member of BARC indicated that after BARC published its first RAP Report Card in 2002, a local politician used it at a city council meeting to demand why more wasn't being done for the restoration of the harbour (Interview with BARC member or affiliate, 2008). Building political will like this is as important a form of recognition of the group, as the recognition by the government.

In addition to recognition by the government, it is also important to have recognition from the public. Through the interviews it was clear that many of the participants felt that the programs that serve to educate the public, especially children, are important such as the Yellow Fish Road program and the Mini Marsh program. The advantages of these programs are that they educate children, who in turn would educate their parents (Interview with BARC member or affiliate, 2008) and they are programs that are visible to the public (Interview with BARC member or affiliate, 2008). Some did suggest that improvements could be made to those programs. For example, with the Yellow Fish Road program, it was suggested that it didn't connect the public to the effects that their 
actions were having on the watershed as much as it could (Interview with BARC member or affiliate, 2008). Regardless of this criticism, these programs have increased the public profile of BARC and the Harbour, and have helped create political will and support for the harbour restoration.

This recognition of the group is important as it ensures that BARC is a collective action group that the government and the public acknowledge as legitimate. If the rights of the group had not been and did not continue to be recognized, it is highly possible, given that this project is very long term (with a goal of delisting in 2015, it means that the life of the project is just over 25 years - a long time to keep stakeholders engaged), that it would have been difficult to continuously engage the stakeholders and government.

\subsection{A new design principle: Distribution of resources (financial and human)}

As this thesis proposes, using Ostrom's design principles to evaluate collective action groups that monitor and remediate polluted resources, as opposed to using a resource for consumption, is possible. But one limitation to using these principles is that resources, both financial and human, are necessary in order to ensure that the pollution is abated, and cleaned up, and that the monitoring of the resource continues once it has been cleaned up or restored. This is something that Ostrom does not directly propose in her design principles but this thesis proposes should be a new design principle specifically for CPRs that are polluted and possibly for other common pool resources that are used by heterogeneous groups of users ${ }^{11}$. Specifically, this new principle means that in

\footnotetext{
${ }^{11}$ Note that the idea of adding a new principle came as a result of feedback from Peter Andrée (thesis committee member) and Stephan Schott (thesis supervisor).
} 
the case of pollution, not only do costs need to be considered for stakeholders that were responsible for pollution, but also for the public as a whole in order to get the community to engage in the process. This means that organizations, such as BARC for example, that monitor the resource and promote its sustainability, need to have funds and staff in order to function. It could be argued that the principle of equivalent costs and benefits contains a provision for resources. But this equivalence in Ostrom's principle is based on an individual level; the costs and benefits are for each stakeholder as opposed to the remediation project as a whole. Also, more of the emphasis of these costs is being placed on remediating pollution, not on ensuring that enough funding is in place for the collective action group to monitor and educate the public about the CPR. The concept of distributing resources, in the case of a CPR that is polluted, is that resources need to be provided at an aggregate level, since it is often difficult to attribute the costs and particularly the benefits to individual stakeholders.

Financial and human resources should be considered as necessary for collective action groups that remediate CPRs because without the financial and human resource support, it is difficult to ensure the success of restoration. The financial resources in particular are important as the funds not only support the remediation of the CPR, but they ensure that staff are available for the collective action group and ensure that funds are available for monitoring the resource in the future. Both active and passive stakeholders play an important role in this principle. Much of this support should come from the active stakeholders, in 
particular the financial support that can fund the technical aspects of remediation as well as fund the staff required to administer the remediation plan. This is in part because these active stakeholders are or have been responsible for much of the pollution. This involves a trade-off on their part because the money that they spend on remediating the CPR would take away financial support for other activities in which the stakeholder might wish to engage in. Despite the high costs that are incurred from the active stakeholders due to their past or current actions, there does need to be more of a financial commitment from the passive stakeholders as they stand to gain from the remediation of the resource. If the passive stakeholders are more active in providing funds (they are often large providers of volunteers but not as much money) it shows the active stakeholders that they are not in this process alone. The passive stakeholders can contribute by volunteering with activities such as monitoring and increasing public awareness, as well as by raising funds to support the collective action group. This does not mean that the passive stakeholders need to be contributing as much as the active stakeholders, but they do need to be contributing. This idea of ensuring that the resources for the restoration project as a whole are available to remediate the CPR can be seen in the case of he Hamilton Harbour.

Support staff and volunteers can play an important role in a collective action group that is remediating a pollution resource. Former and current members of BARC indicated that one challenge that the Hamilton Harbour RAP faces is that both staff members and volunteers have a lot of work on their plates. Some indicated that new programs such as Adopt-A-Creek are often more 
difficult to start because the staff already are busy with so many of the other programs that BARC is in charge of. In addition, it was suggested that while volunteers were enthusiastic and devoted to the cause, that in general, volunteerism in Canada is on the decline, and that the concern was that it was becoming increasingly difficult to get new volunteers, and not to overwork the volunteers that had already committed to the cause. It was also suggested that BARC re-evaluate the needs of the group, as well as their staffing levels for each program and their overall strategy in order to ensure that they are focusing their time and money on programs that will be the most beneficial to achieving their goal of delisting by 2015 (Interview with BARC member or affiliate, 2008). Human resources is certainly a concern for the Hamilton Harbour RAP, and is one issue that is not as fully explored in the work that Ostrom has conducted, possibly because she focuses on CPR management regimes that manage the resource from within: stakeholder participation in her examples may be a result of the fact that stakeholders gain direct and immediate benefits from participating in the group. Such is not the case for BARC, as it requires a large number of volunteers, as well as their, limited staff to put in a lot of time to get the work done. Attracting volunteers and staff to a program for which there are no immediate direct financial benefits, and where the costs are high, is arguably more difficult, and makes the case of the Hamilton Harbour distinct from the examples that Elinor Ostrom has based her design principles on.

Funding appears to be one of the top challenges that the Hamilton Harbour RAP faces, in particular funding until the harbour is delisted. It was 
made evident in the interviews and in the documents that BARC could do much more if it had more funding, in particular it could hire more staff in order to deal with some of the workload. In one of the annual reports, the report indicated that the staff, in addition to working their "paid" hours, also spent countless hours volunteering their time in order to get all of the goals achieved. Consistent funding would also ensure that when a sponsor discontinues one of its activities, such as the RBG discontinuing its greenhouse program which led to a temporary stall in the Mini Marsh program (Interview with BARC member or affiliate, 2008), that it could cover that loss in the interim until a new sponsor was found, rather than putting the program on hold. Funding should also be the responsibility of the passive stakeholders, the stakeholders that do not have property rights in the CPR but who would benefit if the pollution is to be remediated. In the case of the Hamilton Harbour, BARC is actively raising funds for the Hamilton Harbour, although it has been more active in recent years than in the past. For example in January 2009, BARC held their second annual Wine Tasting and Silent Auction, which had a great turnout (Bringing Back the Bay, Winter 2009). BARC needs to continue events like this in order to ensure that it has funds to continue its work.

Funding for the group in the future, once the harbour is delisted as an $A O C$, is also a concern. Government funding for the group ends once the RAP is delisted, which means that BARC needs to ensure that it has strong fundraising capabilities in place before that deadline. At the time of writing this report it is not clear if government funding will continue in order to ensure that harbour conditions are monitored in the future. BARC is committed to ensuring that long- 
term monitoring continues. BARC does receive funding from grants, such as the Ontario Trillium Foundation, however, that is only to support BARC, and not to support the remediation activities that are required to restore the harbour. This is one issue that Ostrom does not address, again because she does not look at pollution remediation cases. What do stakeholder groups do when the resource has been restored, and funding withdrawn, yet the group is still required to maintain the sustainability of the resource? This is why an additional principle is necessary. The resources need to be provided for by all the stakeholders, both passive and active, and the funding needs to continue once the formal agreement to clean up the resource is fulfilled, as the resource should continue to be monitored.

\subsection{Summary}

CPRs are difficult to manage. However, managing them is possible, as Ostrom outlined with her key principles for governing a sustainable resource management regime. These design principles provide a framework for managing a CPR, but because each CPR and its community are different, it is important to remember that these principles are a general guideline. If a plan to govern a CPR is built using these principles, then based on the research conducted by Ostrom and other academics, it has a greater chance of being a success. This chapter illustrates that by applying these design principles to Hamilton Harbour, it is possible to identify some areas in which the Hamilton Harbour has run into some challenge. The Hamilton Harbour meets the principles such as having a well-defined boundary, forming a collective choice arrangement, monitoring the 
resource, as well as having their right to organize be recognized by the government.

The areas in which the Hamilton Harbour has had difficulties include its ability to provide an equivalence between the costs and benefits of remediating the resource. This is in part due to the nature of the problem that faces the Hamilton Harbour; remediating pollution is arguably a more difficult thing to convince stakeholders to do because they have to fund a large portion of the clean-up before they can start to see some of the benefits, be they financial or intrinsic. In addition Hamilton Harbour has for the most part fulfilled the principle of a collective choice arrangement, but there is the issue of BARC and BAIT, and the power imbalance that exists with that arrangement. The Hamilton Harbour RAP also has trouble with the graduated sanctions: there is no formal system for sanctioning the members from within other than peer pressure. Also there are no formal conflict resolution mechanisms, which can encourage power imbalances in the group. Because the nature of a CPR that is used as a pollution sink is different from that used as a commodity (as in most cases that Ostrom examines) this thesis proposes that another principle be added to the list - that of ensuring that resources (financial and human) are available to ensure the viability of the collective action group. As the case of the Hamilton Harbour illustrates, the issue of resources presents some challenges that the RAP must overcome. The following chapter summarizes the results of this thesis and provides some recommendations for the Hamilton Harbour RAP as well as other collective action groups that seek to address pollution of a CPR. 


\section{Chapter 6 Recommendations}

The purpose of this thesis is to examine the Hamilton Harbour Remedial Action Plan and the stakeholder group that is responsible for overseeing the implementation of the remediation, in order to determine how well it meets Ostrom's design principles for a successful CPR regime. In particular this thesis examines the challenges or barriers to success that the remediation of the harbour has encountered, and attempts to link these challenges to the inability of the RAP to meet some of her design principles. This is important because Ostrom has mainly looked at cases in which the resource was used for consumption; in the case of the Hamilton Harbour the purpose of the CPR regime is to remediate pollution, with the intent of making the resource useable for future generations. This following chapter makes recommendations on areas in which the Hamilton Harbour RAP could be improved.

\subsection{Review of Thesis}

To understand the problem in the Hamilton Harbour, a history of not only the harbour but also the key agreements that established the BARC and the federal and provincial laws that monitor and regulate pollution is discussed in chapter three. This discussion was important because as we learned, the GLWQA stipulated that both the Canadian and American governments should make sure to include the community as participants in the remedial action plan. This in essence led to the establishment of not only the RAP for the Hamilton Harbour but also to BARC and BAIT. This illustrates how there was formal recognition of the right for the group to organize, meeting Ostrom's seventh 
principle. In addition this section outlined the importance of understanding each regulation that was in place because these regulations help define the rules under which the Hamilton Harbour RAP operates.

The next chapter of the thesis outlined the structure and beginning of BARC as well as BAIT. It helps us to understand the conditions under which BARC was formed, showing that while the federal government initiated the formation of the stakeholder group, it was the stakeholders themselves who developed the RAP. The stakeholders, while being supported by the government, established the RAP, and subsequently BARC and BAIT, and lived up to and met the Ostrom's principle of establishing a collective choice agreement. While initially formed under the guidance of Environment Canada, the stakeholders quickly became a group that took control of the RAP and made it their own. The role of Environment Canada was to provide technical assistance, and they left the negotiations of what to include in the RAP to the group. This is potentially a key element to why the group has stayed together as long as it has. Because the group was self-determined, all members felt that their ideas were being heard. This concept is still being followed today, in that BARC takes the moderate position in order to ensure that all group members are being represented and not favouring one stakeholder member's opinion more than others. One issue that is defined in this chapter is that there seems to be an imbalance of power. This has had an effect on one of the major RAP recommendations, cleaning the contaminated sediment in Randle's Reef. 
As mentioned above, the principles that Elinor Ostrom and other theorists have laid out as being integral to the development of a sustainable common property resource, such as water in the Hamilton Harbour, were explored in this section. There are seven main principles that Ostrom and her colleagues have outlined. Of these seven design principles, this thesis shows that four (well defined boundaries, the establishment of a collective choice agreement, monitoring, and the recognition of rights to organize) are fulfilled based on an analysis of the RAP documentation. The remaining three principles are not met. This includes the absence of equivalence between the costs and benefits of remediation, graduated sanctions, and conflict resolution mechanisms. The importance of these finding is that first, it indicates that while the Hamilton Harbour RAP has been a strong collective action group, there are some areas in which it could improve in order to ensure its success. Second, this research indicates that there are some principles for collective action resources that monitor and remediate pollution that are different from those that use the CPR as a commodity for consumption. In particular, this thesis proposes that human resources and financial support are integral to ensure the success of a collective action group that remediates a polluted CPR. This was seen with the case of the Hamilton Harbour, which has faced funding shortages, and has overworked yet dedicated staff and volunteers. This has created challenges for the group, and as is examined at the end of this chapter, leads to recommendations for the group. 


\subsection{Recommendations}

1. The RAP needs to include sanctions.

As mentioned above, because the two levels of government are responsible for the regulations that determine the levels of pollutants that can be released by the companies and the city into the harbour, it also has the responsibility to enforce those regulations. The TSH used to act as a tool for monitoring the resource, however this is not the case anymore. This author recommends that the group return to naming those who are not meeting their obligations under the RAP. This was effective in the past, at least in terms of getting members to work towards their goals. It would also work towards ensuring that cheating, as was the case with the Rennie Street Dump, could be avoided. The one problem with this recommendation is that it could end up alienating some of the key stakeholders. However, there is much more public awareness of the Hamilton Harbour RAP now then there was when the TSH did name names. This could translate into stakeholders wanting to ensure that they are not perceived in a negative fashion by the public, and thus they could remain committed to their obligations.

I would also add that the report cards, which are more obvious indicators of how the remediation is working, should be more frequent, especially as it gets closer to the desired date of delisting for the group (2015). The stakeholders who are responsible for meeting their targets need to be held more publicly accountable and the report card is a clear indicator of which goals are not being met. While it is important to work with the stakeholders and to avoid alienating 
them, it is also important to ensure that the respect is mutual, and that stakeholders do not take advantage of the lack of "finger pointing" towards stakeholders that do not meet their obligations. These sanctions could encourage better participation. Also noted that some stakeholders did not like the fact that BARC has become a moderate voice, and those who felt that they could not abide by the moderate voice, have since left the organization (Interview with BARC member or affiliate, 2008). This means that the group is starting to alienate the passive stakeholders and is losing credibility in with some areas of the public. Drawing the line between moderation and being critical of those who do not meet their expected goals for the restoration of the harbour is a difficult one; there is no easy solution. Both actions risk alienating the stakeholders.

2. A formal conflict resolution mechanism needs to be put in place to deal with conflicts between stakeholders.

As the members of this group have emphasized, one of the main ways in which the group avoids conflict is to ensure that each issue is discussed completely. It may take more than one meeting in order to resolve a conflict, however once a decision is reached, it is because the majority of the group believes in the decision that has been made. As one participant has stated, the fact that all stakeholders are able to engage in that debate ultimately leads to a great buy in to the plans that the group implements, leading to a smaller chance that there will be conflict in the future. One could argue that a more formal method should exist, however based on what I have learned from this organization both in interviews and through discussion, is that the main reason 
for conflict seems to be a lack of communication, i.e. stakeholders knowing they have been polluting, but not letting the group know, or stakeholders cutting funding, but again, not informing the stakeholders. Going back to the point above, if there was a sanction that the group itself could impose, it might help resolve these conflicts in the future, and reduce negative feelings.

The one concern is that one of the mechanisms used to resolve conflict seems to have been that if groups do not agree with decisions that are being made or the direction that the group is taking, that they then in turn may decide to leave the group. This is a dangerous pattern, because it could ultimately disrupt the legitimacy of the stakeholder group, and could start to exclude the "other" voice, in important to the stakeholders that have more of a financial or legal ownership of the resource. It is for this reason that a more formal mechanism needs to be in place. This could be in the form of a special committee composed of a broad range of stakeholders as well as an independent member, that only meets on an ad hoc basis in order to listen to and to offer suggestions to any conflicts that might arise, such as is the case of Randle's Reef. Having such a committee would only be possible if all members agreed that this was the best method in which to resolve conflicts, otherwise this committee would not be credible.

3. The Hamilton Harbour RAP should attempt to eliminate divisions in the level of power of the stakeholders, perhaps by increasing the membership of BAIT. Citizens at large, recreational group's, community groups and environmental groups do not have direct ownership in the harbour or the surrounding land (with 
the exception of some private landowners) and as a result, it is difficult for them to have more of a say in how the implementation of the goals should happened if they are not included in BAIT. This was seen in the case of Randle's Reef. If their voice is missing, the legitimacy of the group could diminish. While these groups are still actively involved in BARC, and BARC is involved in BAIT, it is still a concern that their concerns might not be heard as equally.

This division between the powerful stakeholders, i.e. the active stakeholders and the less powerful stakeholders (passive) could be resolved in one of two ways. The first is that BAIT could be dissolved, and BARC could take over the responsibility of implementation, thus allowing the passive stakeholders a chance to participate in those activities. Another option would be to include passive stakeholders in BAIT. In both cases, this may help to reduce conflict that arises on certain issues that the group faces.

4. The benefits of participating in the RAP needs to be better defined.

The Hamilton Harbour RAP needs to better define the benefits of participating in the RAP. As illustrated in chapter five, the proportional equivalence between costs and benefits is important for common-pool resources, especially the Hamilton Harbour RAP since stakeholders need to be convinced as to why their participation is necessary. The harbour is a sink for pollution and the RAP requires funding to fix the harbour, however, the amount of income earned from this is limited. Much of the value of remediating the harbour is that it would be returning the harbour to its natural state, a state that is more enjoyable for the local residents as well as the wildlife. One could argue that if the harbour is 
restored, there would be more public events held at the harbour, which in turn would generate tourism dollars but this has not yet been estimated for the harbour. A more comprehensive cost-benefit analysis could provide an extra incentive for stakeholders to maintain their financial commitment to remediation. This would especially be useful when the economy is suffering through a recession. It should be noted here that one avenue of this case that should be explored is whether or not there is a trade-off for industry between retaining jobs at the factories versus expenditures on pollution abatement technologies as well as remediating the contaminated CPR. For example, in the case of the Hamilton Harbour, does the participation of two large employers such as Stelco and Dofasco in the RAP mean that they are unable to retain jobs or vice versa? This is an avenue that should be explored in future research.

5. Consistent funding from the federal and provincial governments.

The provincial and federal governments need to ensure that funding remains consistent for not just the Hamilton Harbour RAP but also all of the AOCs in Ontario. They need to ensure that funds are available for the stakeholder groups to continue to operate, so that they can afford to pay the salaries of staff members that are integral to ensuring that the commitments of the RAP are fulfilled. In addition, once the RAP is delisted, government needs to ensure that funding is available for monitoring. This will ensure that if the conditions in the harbour start to deteriorate in the future, that it will be noticed before the problem gets as bad as it was when the Hamilton Harbour was first recognized as an $A O C$ in the mid-eighties. The two levels of government also need to ensure that 
pollution regulations are enforced, again, to avoid further harming Canada's freshwater supply.

\subsection{Conclusion}

It is hard to measure the success of a group such as BARC in meeting its goals, and whether or not it has been effective, but that is not what this paper has attempted to do. Rather, this paper has attempted to understand how this group works, and to evaluate where this groups stands in relation to Ostrom's design principles that provide a framework for which criteria help to ensure that a collective action group for a common pool resource is sustainable. In particular this thesis has used the case of the Hamilton Harbour RAP to show how Ostrom's principles can be applied to a CPR that is being used as a pollution sink.

As was mentioned at the beginning of this paper, the case of the Hamilton Harbour is much different from other cases that are generally studying in the literature on common pool resource management because in this case it is all about remediation the damage that has already been done as a result of poor management, not on ensuring that the resources can be used for direct financial gain. Mark Sproule-Jones has done extensive research on the role that government has played in CPR institutions such as the Hamilton Harbour RAP, and the role of property rights and rules. This thesis adds to his research by applying all of the design principles to the Hamilton Harbour RAP, in order to understand the challenges that it faces. Lessons from this group can be learned 
in order to help not only other RAPs around the Great Lakes but also to help other groups that are not just managing the consumption of a resource, but are remediation the effects of over consumption and pollution. With this research we have seen that in addition to the principles that Ostrom outlines as general guidelines to follow when designing a collective action group, in the case of polluted resources, it is important to consider how the remediation of the CPR will be funded and to provide support staff to ensure oversee the work.

The work that has been done by the stakeholders in the Hamilton Harbour has been impressive. Hamilton Harbour has been an eyesore in the Hamilton cityscape for a long time, and to improve the appearance and more important the quality of the water is an important task, and one that the group has not taken lightly. This group has succeeded in keeping the Hamilton Harbour in the public eye, increasing their membership, and creating the political will to keep the issues of the Hamilton Harbour at the forefront.

The success of the remediation of the Hamilton Harbour is an important goal, for a few reasons. The most evident is that industry and cities need to take responsibility for the pollution that has been caused and not only find ways to prevent it in the future but also to clean it up. The second reason, which is integral to this thesis is that the success of the Hamilton Harbour will be in no small part due to the group of dedicated stakeholders and volunteers who not only determined the direction in which they wanted to take in order to remediate the harbour but also determined the methods for reaching those goals. But the harbour has not been restored yet, and the group admits that while the goal of 
achieving a delisted RAP status in 2015 is steep, it is possible. Given that water is a precious resource, and is important for the well being of all people it is important that the water is in a condition that be used without causing health problems. For too long people have taken resources for granted. This group shows that it is possible work together towards a common goal, that of improving their local environment. 


\section{Appendix A - Beneficial Use Impairments for the Great Lakes Area's of Concern}

Impairment of beneficial use(s) means a change in the chemical, physical or biological integrity of the Great Lakes System sufficient to cause any of the following:

I. restrictions on fish and wildlife consumption;

II. tainting of fish and wildlife flavour (NA to the HH RAP)

III. Degradation of fish wildlife populations;

IV. fish tumors or other deformities;

$V$. bird or animal deformities or reproduction problems;

VI. Degradation of benthos;

VII. restrictions on dredging activities;

VIII. eutrophication or undesirable algae;

IX. restrictions on drinking water consumption, or taste and odour problems;

$X$. beach closings;

$X I$. Degradation of aesthetics;

XII. added costs to agriculture or industry;

XIII. Degradation of phytoplankton and zooplankton populations; and

XIV. loss of fish and wildlife habitat.

International Joint Commission, The Great Lakes Water Quality Agreement http://www.ijc.org/rel/agree/quality.html\#ann2,(accessed January 24, 2009). 


\section{Appendix B - Remedial Action Plans}

The Parties shall cooperate with State and Provincial Governments to ensure that Remedial Action Plans are developed and implemented for Areas of Concern. Each plan shall include:

i. a definition and detailed description of the environmental problem in the Areas of Concern, including a definition of the beneficial uses that are impaired, the degree of impairment and the geographic extent of such impairment;

ii. a definition of the causes of the use impairment, including a description of all known sources of pollutants involved and an evaluation of other possible sources;

iii. an evaluation of remedial measures in place;

iv. an evaluation of alternative additional measures to restore beneficial uses;

v. a selection of additional remedial measures to restore beneficial uses and a schedule for their implementation;

vi. an identification of the persons or agencies responsible for implementation of remedial measures;

vii. a process for evaluating remedial measure implementation and effectiveness; and

viii. a description of surveillance and monitoring processes to track the effectiveness of remedial measures and the eventual confirmation of the restoration of uses. (IJC, GLWQA 1978, Annex 2, http://www.jic.org/rel/agree/quality.html\#ann2, Accessed January 27, 2009) 
Appendix C - Map of Hamilton Harbour in 1835

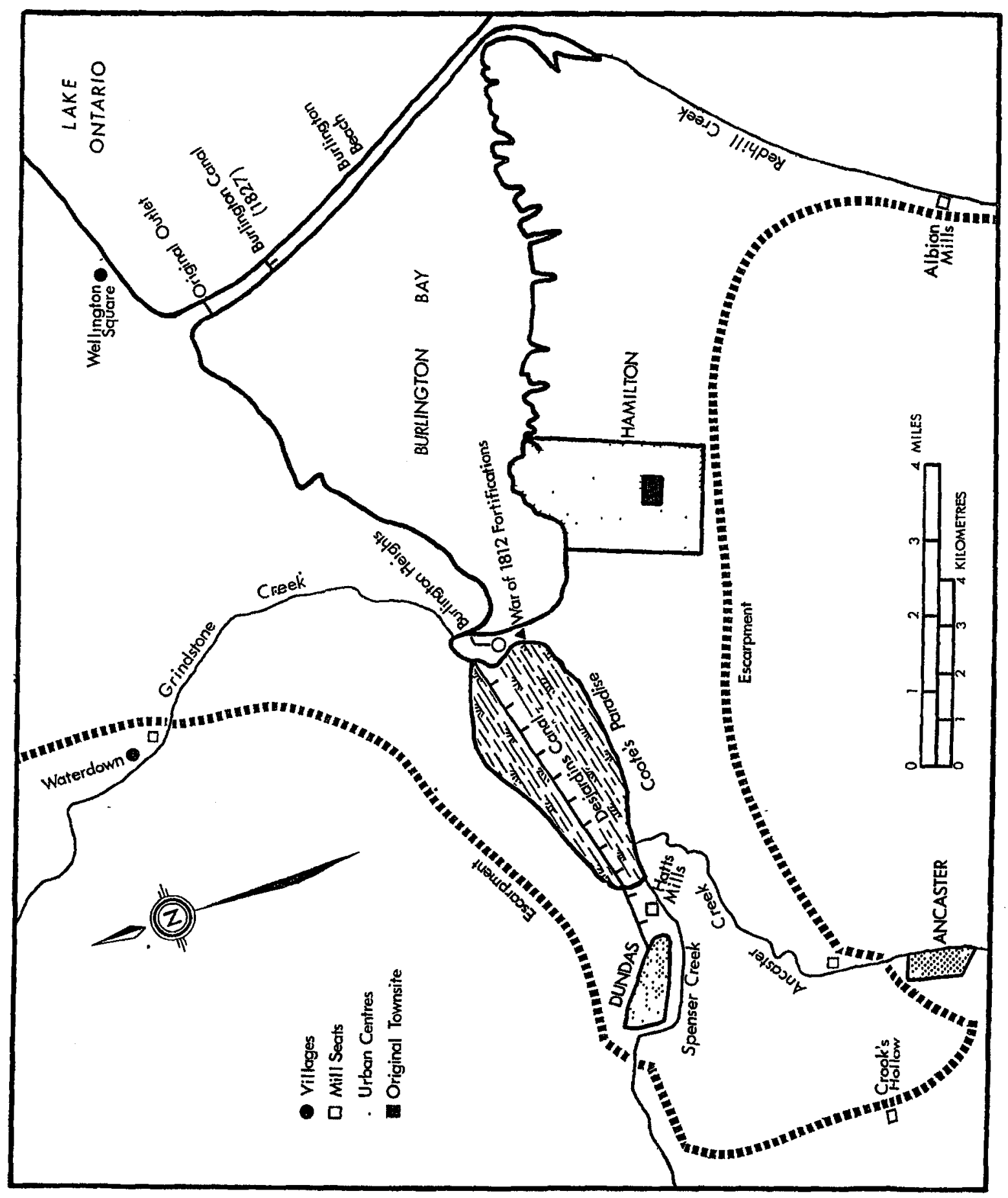

Weaver, John C. Hamilton: An Illustrated History. Toronto: James Lorimer \& Company: 1982, p 21. 


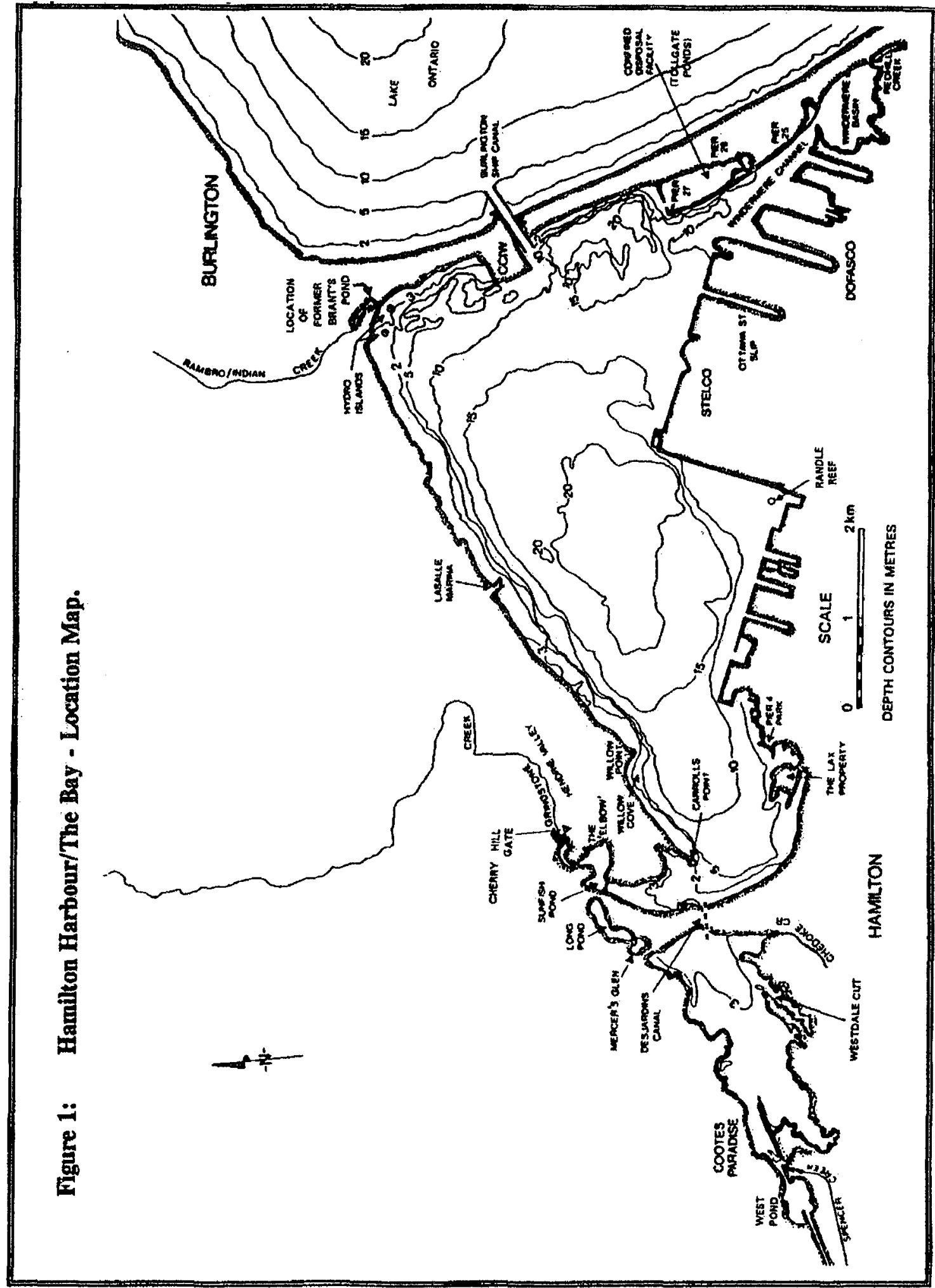

Hamilton Harbour Remedial Action Plan Writing Team. Remedial Action Plan for Hamilton Harbour: Environmental Conditions and Problem Definition, Second Edition of the Stage 1 Report. 1992: http://www.hamiltonharbour.ca/rap/reports.htm (accessed January 18, 2009), pg 8. 


\section{Appendix E - The questions for the members of the Bay Area Restoration Council (BARC):}

1. Name

2. Position within BARC

3. How many years have you been a member of BARC?

4. Which organization do you represent?

5. How long have you been involved with that organization?

6. Briefly describe your academic background.

7. How often does the Board of Directors meet? How often do the committees meet?

8. Are positions in BARC filled with:

a. Enthusiastic and experienced volunteers?

b. Enthusiastic but less experienced volunteers?

9. How is the membership of the board of directors determined?

10. Please describe the role that you play within BARC.

11. How long have you been involved with your stakeholder organization?

12. How would you describe the role that your stakeholder organization plays within BARC?

13. Is there a mechanism within BARC that deals with conflict within the group? If yes, please describe it.

14. Is there a mechanism within BARC that deals with conflict between BARC and the BARC member organizations (listed on the BARC website)? If yes, please describe it.

15. Which of the programs that BARC has implemented in order to improve the quality of the water in the Hamilton Harbour do you deem to be most successful and why?

16. Which of the programs that BARC has implemented in order to improve the quality of the water in the Hamilton Harbour do you deem to be most unsuccessful and why? What do you think could be done to improve that? What do you think went wrong with the program?

17. Each year BARC produces annual reports on the progress of the RAPs - do you feel that the reports are a helpful tool in forwarding the goal of cleaning up the harbour?

18. How does BARC interact with the Municipal governments that surround the Hamilton Harbour?

19. How does BARC interact with the Ontario Ministry of the Environment?

20. How does BARC interact with the federal government?

21. How does BARC interact with the International Joint Commission?

22. BARC is involved in various outside groups, one of which is Great Lakes United - could you describe the relationship of those groups to BARC? Do you feel that BARC is a respected member of those groups?

23. In what direction do you see BARC moving in order to maintain the level of active work in order to improve the water quality of the Bay?

24. What kinds of barriers to progress does BARC encounter in its activities related to the RAP? In it's other activities? 


\section{Appendix F - Questions for the members of partner organizations of BARC}

1. Name

2. Name of partnership organization

3. Position within that partnership organization

4. How long have you worked/volunteered at the organization?

5. Please describe the role that you play within the organization

6. How would you describe the role that your stakeholder organization plays within BARC?

7. Please describe your involvement with BARC, as a representative of your organization

8. Which of the programs that BARC has implemented in order to improve the quality of the water in the Hamilton Harbour do you deem to be most successful and why?

9. Which of the programs that BARC has implemented in order to improve the quality of the water in the Hamilton Harbour do you deem to be most unsuccessful and why? What do you think could be done to improve that? What do you think went wrong with the program?

10. In your opinion, what makes BARC, as a stakeholder group, successful?

11. Each year BARC produces annual reports on the progress of the RAPs - do you feel that the reports are a helpful tool in forwarding the goal of cleaning up the harbour?

12. In what direction do you see BARC moving in order to maintain the level of active work in order to improve the water quality of the Bay?

13. What kinds of barriers to progress does BARC encounter in its activities related to the RAP? In it's other activities? 


\section{Appendix G - Questions for the member of the International Joint Commission (IJC)}

1. Name

2. Position within IJC

3. How long have you worked on the IJC?

4. Please describe the role that you play within the IJC

5. What type of work do you perform at the IJC?

6. In your position at the IJC, how many RAP's are you involved with?

7. In your opinion, what makes a RAP successful?

8. Based on your opinion, are there some community stakeholder organizations that are more effective than others in implementing the RAP's in their respective locations?

9. How does BARC compare to other stakeholder organizations in its ability to monitor the RAP?

10. In your opinion, is BARC an effective community group compared to other community groups that monitor the RAPs around the Great Lakes?

11. What types of barriers are there to success for these community groups when monitoring the implementation of the RAP? How do these community groups deal with these barriers i.e. how do they attempt to overcome these barriers? 


\section{Works Cited}

Adger, W. Neil, Katrina Brown, and Emma L. Tompkins. "The Political Economy of Cross-Scale Linkages in Resource Co-Management" in Economy and Society 10, no. 2 (2005). http://www.ecologyandsociety.org/vol10/iss2/art9/ (accessed February 4, 2009).

Agrawal, Arun, and Clark Gibson. "Enchantment and Disenchantment: The Role of Community in Natural Resource Conservation" in World Development 27, no. 4 (1999): 629-649.

Baland, Jean-Marie, and Jean-Philippe Platteau. Halting Degradation of Natural Resources - Is There a Role for Rural Communities? Oxford: Oxford University Press, 2000.

http://dx.doi.org.proxy.library.carleton.ca/10.1093/0198290616.001.0001 (accessed February 16, 2009).

Bay Area Restoration Council. www.hamiltonharbour.ca (accessed January 29, 2009)

Bay Area Restoration Council, Annual Report. 2000-2001 to 2007-2008. www.hamiltonharbour.ca, (accessed April 14, 2008).

Bay Area Restoration Council, Annual Report. (Hamilton: Bay Area Restoration Council, 1991-1992 to 1999-2000).

Bay Area Restoration Council, Bringing Back the Bay. 2000-2008. www.hamiltonharbour.ca, (accessed April 14, 2008).

Bay Area Restoration Council, Bringing Back the Bay. (Hamilton: Bay Area Restoration Council, 1994-1999).

Bay Area Restoration Council, Toward Safe Harbours Report Card. 2002. www.hamiltonharbour.ca, (accessed April 14, 2008).

Bay Area Restoration Council, Toward Safe Harbours Report Card. 2007. www.hamiltonharbour.ca, (accessed April 14, 2008).

Bay Area Restoration Council, Toward Safe Harbours Report. 2000, 2003-2006, and 2008. www.hamiltonharbour.ca, (accessed April 14, 2008).

Bay Area Restoration Council, Toward Safe Harbours Report. (Hamilton: Bay Area Restoration Council, 1994-1999). 
Beierle, Thomas C. Public Participation in Environmental Decisions: An Evaluation Framework Using Social Goals. Washington, DC: Resources for the Future Discussion paper 99-06, 1998. http://ageconsearch.umn.edu/bitstream/10497/1/dp990006.pdf (accessed November 25, 2008).

Bixby, Alice. "The Great Lakes Water Quality Agreement and Areas of Concern: A Program Audit for Assessing an Institution". MA Research Paper, University of Toronto, 1985.

Botts, Lee and Paul Muldoon. The Great Lakes Water Quality Agreement: Its Past Successes and Uncertain Future. New Hampshire: The Institute of International Environmental Governance, 1996.

Botts, Lee and Paul Muldoon. Evolution of the Great Lakes Water Quality Agreement. East Lansing: University of Michigan Press, 2005.

Bowers, C.A. Revitalizing the Commons: Cultural and Educational Sites of Resistance and Affirmation. Lanham: Lexington Books, 2006.

Carr, Deborah S. and Kathleen Halvorsen. "An Evaluation of Three Democratic, Community-Based Approaches to Citizen Participation: Surveys, Conversations with Community Groups, and Community Dinners" in Society and Natural Resources 14 (2001):107-226.

Christensen, Randy and Anastasia M. Lintner. "Trading our Common Heritage? The Debate over Water Rights Transfers in Canada" in Eau Canada: The Future of Canada's Water, edited by Karen Bakker, 219-244. Vancouver: UBC Press, 2006.

Department of Justice. The Canada Water Act. http://laws.justice.gc.ca/en/C11/index.html (accessed March 29, 2009).

Dickinson, Brock H. Toward Safe Harbours: Tracking the Implementation of the Remedial Action Plan for Hamilton Harbour. Hamilton: Bay Area Restoration Council, 1995.

Dolsak, Nives and Elinor Ostrom. "The Challenges of the Commons" in The Commons in the New Millenium: Challenges and Adaptations, edited by Nives Dolsak and Elinor Ostrom, 3-34. Cambridge: The MIT Press, 2003.

Environment Canada (a). CEPA Environmental Registry. http://www.ec.gc.ca/cepaRegistryl (accessed February 20, 2009).

Environment Canada (b). The Canada-Ontario Agreement Respecting the Great Lakes Basin Ecosystem. 
http://www.on.ec.gc.ca/greatlakes/default.asp?lang=En\&n=EA1818251\#agreement, (accessed January 25, 2009).

Environment Canada (c). Canadian Remedial Action Plans. http://www.ec.gc.ca/raps-pas/default.asp?lang=En\&n=A290294A-1 (accessed February 21, 2009).

Environment Canada (d). Great Lakes Portraits: Lake Erie. www.on.ec.gc.ca/laws/coa/2001/lake-erie-e.html (accessed February 20, 2009).

Environment Canada (e), Introduction: Great Lakes Charter Annex Implementing Agreements.

http://www.on.ec.gc.ca/greatlakes/default.asp?lang=En\&n=BA0D657B-1, (accessed January 25, 2009).

Environment Canada (f). Lakewide Management Plans (LaMPs), http://www.on.ec.gc.ca/greatlakes/default.asp?lang=En\&n=324C092F-1 (accessed March 22, 2009).

Environment Canada (f). The Management of Water: The Pollution Problem. www.ec.gc.ca/WATER/en/manage/poll/e problm.htm (accessed February $17,2009)$.

Environment Canada (g). The Management of Water: The Great Lakes - $A$ Chemical Hot Spot, www.ec.gc.ca/water/en/manage/poll/e hotspt.htm (accessed April 20, 2008).

Environment Canada (h). Canada's RAP progress Report 2003: Hamilton Harbour. http://www.ec.gc.ca/rapspas/default.asp?lang=En\&n=D91BD30F-1\&offset=14\&toc=show, (accessed February 21, 2009).

Evans, Lois. Hamilton: The Story of a City. Toronto: The Ryerson Press, 1970.

Government of Canada. Great Lakes Water Quality Agreement. http://www.on.ec.gc.ca/greatlakes/default.asp?lang=En\&n=FD65DFE5-1 (Accessed December 6, 2008).

Grimble, Robin and Kate Wellard. "Stakeholder Methodologies in Natural Resource Management: A Review of Principles, Contexts, Experiences, and Opportunities" in Agricultural Systems 55, no. 2, (1997): 173-193.

Hall, John D., Kristin O'Connor, and Joanna Ranier. "Progress Toward Delisting a Great Lakes Area of Concern: The Role of Integrated Research and 
Monitoring in the Hamilton Harbour Remedial Action Plan" in

Environmental Monitoring and Assessment 113, no. 1-3 (2006): 227-243.

Hamilton Economic Development (a). City Profile: Industry Sectors. http://www.investinhamilton.ca/industrysectors.asp, (accessed February 21, 2009).

Hamilton Economic Development (b). Port of Hamilton: Industry profile, http://www.investinhamilton.ca/Pdf/PortProfiles.pdf, (accessed February $21,2009)$.

Hamilton Harbour RAP Implementation Team. Remedial Action Plan for Hamilton Harbour: 1998 Status Report. Environment Canada: Hamilton, 1998.

Hamilton Harbour Remedial Action Plan Stakeholders and Technical Team. Remedial Action Plan for Hamilton Harbour: Goals, Options and Recommendations, Volume 2 - Main Report. 1992: http://www.hamiltonharbour.ca/rap/reports.htm (accessed January 30, 2009).

Hamilton Harbour Remedial Action Plan Stakeholder Forum. Remedial Action Plan for Hamilton Harbour: Stage 2 Update 2002. 2003: http://www.hamiltonharbour.ca/rap/reports.htm (accessed January 30, 2009).

Hamilton Harbour Remedial Action Plan Writing Team. Remedial Action Plan for Hamilton Harbour: Environmental Conditions and Problem Definition, Second Edition of the Stage 1 Report. 1992:

http://www.hamiltonharbour.ca/rap/reports.htm (accessed January 18, 2009).

Hardin, Garrett. "The Tragedy of the Commons" in Science 162 (1968): 12431248.

Harris, Victoria. "From Plan to Action: The Green Bay Experience" in Under RAPs: Toward Grassroots Ecological Democracy in the Great Lakes Basin edited by John H. Hartig and Michael A. Zarull, 37-56. Ann Arbour: The University of Michigan Press, 1992.

Hartig, John H. and Michael A Zarull (a). "A Great Lakes Mission" in Under RAPs: Toward Grassroots Ecological Democracy in the Great Lakes Basin edited by John H. Hartig and Michael A. Zarull, 5-35. Ann Arbour: The University of Michigan Press, 1992. 
Hartig, John H. and Michael A Zarull (b). "Keystones for Success" in Under RAPs: Toward Grassroots Ecological Democracy in the Great Lakes Basin edited by John H. Hartig and Michael A. Zarull, 263-280. Ann Arbour: The University of Michigan Press, 1992.

Inscho, Frederick R. and Mary H. Durfee. "The Troubled Renewal of the Canada-Ontario Agreement Respecting the Great Lakes Water Quality" in Publius 25, no. 1, (1995): 51-69.

International Joint Commission (a). The Great Lakes Water Quality Agreement (last revised 1985). www.jijc.org (accessed November 8, 2008).

International Joint Commission (b). "Status of Restoration Activities in Great Lakes Areas of Concern: A Special Report, April 2003" www.ijc.org (accessed September 28, 2008).

International Joint Commission (c). "Who we are" www.ijc.org, (accessed January 24, 2009).

International Sailing Federation, "Championships setting sail in Hamilton Harbour", March 13, 2007, http://www.sailing.org/news/18322.php?PHPSESSID $=48 \mathrm{c} 580 \mathrm{ff} 1$ abe $808 \mathrm{c4}$ $1192799329 \mathrm{~b} 3671$ (accessed February 28, 2009)

Jackson, John. "Great Lakes Hotspots: Ontario Citizens Speak Up, October 2006". Ontario Public Advisory Council, http://www.citizensrapinfo.ca/reports/report.pdf (accessed August 15, 2008).

Johns, Carolyn, and Ken Rasmussen. "Institutions for Water Resource Management in Canada" in Canadian Water Politics: Conflicts and Institutions edited by Mark Sproule-Jones, Carolyn Johns, and B. Timothy Heinmiller, 59-90. Montreal: McGill University Press, 2008.

Johns, Carolyn, Mark Spropule-Jones, and B. Timothy Heinmiller. "Water as a Multiple Use Resource and Source of Political Conflict" in Canadian Water Politics: Conflicts and Institutions edited by Mark Sproule-Jones, Carolyn Johns, and B. Timothy Heinmiller, 19-58. Montreal: McGill University Press, 2008.

Kaemmerer, Dan, Audrey O'Brien, Tom Sheffy, and Steve Skavroneck. "The Quest for Clean Water: The Milwaukee Estuary Remedial Action Plan" in Under RAPs: Toward Grassroots Ecological Democracy in the Great Lakes Basin edited by John H. Hartig and Michael A. Zarull, 139-160. Ann Arbour: The University of Michigan Press, 1992. 
Kopelman, Shirli, J. Mark Weber, and David M. Messick. "Factors Influencing Cooperation in Commons Dilemmas: A Review of Experimental Psychological Research" in The Drama of the Commons, edited by E. Ostrom, T. Dietz, N. Dolsak, P.C. Stern, S. Stovich and E.U. Weber 113156 (Washington: National Academy Press, 2002.

Leach, Melissa, Robin Mearns, and lan Scoones. "Environmental Entitlements: Dynamics and Institutions in Community-Based Natural Resources Management" in World Development 27, no. 2 (1999): 224-247.

Lovecraft, Amy Lauren. "Transnational Environmental Management: USCanadian Institutions at the Interlocal Scale" in The American Review of Canadian Studies 37, no. 2 (2007): 218-245.

Machan, Tibor. The Commons: Its Tragedies and Other Follies. Stanford: Hoover Institution Press, 2001.

Macleod, Meredith. "Every lost job pushes others into crisis: Local economy will feel the effects" in The Hamilton Spectator, March 4, 2009 http://thespec.metrolandwest.com/News/Business/article/524187 (accessed March 27, 2009)

McMaster University. Hamilton Harbour: Fishing and Recreation, http://www.science.mcmaster.ca/Biology/Harbour/recreat/HEADPAGE.HTM (accessed February 21, 2009).

Ontario Ministry of the Environment (a). Environmental Approvals for Business. http://www.ene.gov.on.ca/en/business/cofa/index.php (accessed February 20, 2009).

Ontario Ministry of the Environment (b). Environmental Penalties - Legislation and Regulations.

http://www.ene.gov.on.ca/en/about/penalties/regulations.php (accessed February 21, 2009).

Ontario Ministry of the Environment (c). Municipal/Industrial Strategy for Abatement. http://www.ene.gov.on.ca/envision/water/misa/index.htm (accessed February 21, 2009).

Ostrom, Elinor. Governing the Commons: The Evolution of Institutions for Collective Action. Cambridge: Cambridge University Press, 1990.

Ostrom, Elinor. Understanding Institutional Diversity. Princeton: Princeton University Press, 2005. 
The Pacific Institute. The World's Water: Information on the World's Freshwater Resources. www.worldwater.org (Accessed February 17, 2009).

Peet, Margaret E., Richard Burton, Richard Elliot, et al. "Rochester Embayment's Water Quality Management Process and Progress, 18871990" in Under RAPs: Toward Grassroots Ecological Democracy in the Great Lakes Basin edited by John H. Hartig and Michael A. Zarull, 185210. Ann Arbour: The University of Michigan Press, 1992.

Phillips, Carol and Mark Sproule-Jones. "Who runs Hamilton Harbour?" Copps Charity Occasional Monograph \#8, Hamilton: 1995.

Rodgers, Keith et al. A Discussion Document of the Goals, Problems, and Options for the Hamilton Harbour Remedial Action Plan. Hamilton: Urban Documentation Centre: Research Unit for Urban Studies McMaster University, 1988.

Schiff, Maurice and Alan Winters. Regional Cooperation, and the Role of International Organizations and Regional Integration (July 2002). World Bank Policy Research Working Paper No. 2872. http://ssrn.com/abstract=636236 (Accessed January 28, 2009).

Schrameck, Roy, Margaret Fields, and Margaret Synk. "Restoring the Rouge" in Under RAPs: Toward Grassroots Ecological Democracy in the Great Lakes Basin edited by John H. Hartig and Michael A. Zarull, 73-92. Ann Arbour: The University of Michigan Press, 1992.

Singleton, Sara. "Cooperation or Capture? The Paradox of Co-management and Community Participation in Natural Resource Management and Environmental Policy Making" in Environmental Politics 9, no. 2 (2000): 121.

Sneddon, Chris. "Water conflicts and River Basins: The Contradictions of CoManagement and Scale in Northeast Thailand" in Society and Natural Resources 15 (2002): 725-741.

Sprague, John B. "Great Wet North? Canada's myth of water abundance" in Eau Canada: The Future of Canada's Water, edited by Karen Bakker, 2336. Vancouver: UBC Press, 2006.

Sproule-Jones, Mark. "Legal Foundations for the uses of the Hamilton Harbour. Hamilton: Copps Chair in Urban Studies, Occasional report No. 2, 1985.

Sproule-Jones, Mark. "Institutional Design for the Economy and the Environment: The Identification and Representation of Stakeholders" in Balancing the Scale: Integrating Environmental and Economic 
Assessment edited by Barry Sadler, Edward W. Manning, and John O. Dendy. Ottawa: Canadian Environmental Assessment Agency, 1995.

Sproule-Jones, Mark (a). Restoration of the Great Lakes: Promises, Practices, Performances. Vancouver: UBC Press, 2002.

Sproule-Jones, Mark (b). "Institutional Experiments in the Restoration of the North American Great Lakes Environment" in Canadian Journal of Political Science, 35, no. 4 (2002): 835-857.

Sproule-Jones, Mark (a). "Politics and Pollution on the Great Lakes: The Cleanup of Hamilton Harbour" in Canadian Water Politics: Conflicts and Institutions edited by Mark Sproule-Jones, Carolyn Johns, and B. Timothy Heinmiller, 179-202. Montreal: McGill University Press, 2008.

Sproule-Jones, Mark (b). "Property Rights and Water" in Canadian Water Politics: Conflicts and Institutions edited by Mark Sproule-Jones, Carolyn Johns, and B. Timothy Heinmiller, 116-133. Montreal: McGill University Press, 2008.

Statistics Canada. 2006 Community Profiles. www.statcan.gc.ca (accessed February 21, 2009).

Stern, Paul C., Thomas Dietz, Nives Dolsak, Elinor Ostrom, and Susan Stonich. "Knowledge and Questions After 15 Years of Research" in The Drama of the Commons, edited by E. Ostrom, T. Dietz, N. Dolsak, P.C. Stern, S. Stovich and E.U. Weber 445-486. Washington: National Academy Press, 2002.

Stride, Frederick, Murray German, Donald Hurley, et al. "An Overview of the Modeling and Public Consultation Processes used to Develop the Bay of Quinte Remedial Action Plan" in Under RAPs: Toward Grassroots Ecological Democracy in the Great Lakes Basin edited by John H. Hartig and Michael A. Zarull, 161-184. Ann Arbour: The University of Michigan Press, 1992.

Wade, Robert. Village Republics: economic conditions for collective action in Southern India. Cambridge: Cambridge University Press, 1988.

Weaver, John C. Hamilton: An Illustrated History. Toronto: James Lorimer \& Company: 1982. 